\title{
Chapter
}

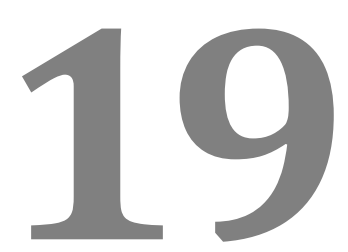

\section{ULTRASOUND-MEDIATED DRUG DELIVERY}

\section{Yufeng Zhou*}

School of Mechanical and Aerospace Engineering, Nanyang

Technological University, Singapore

*E-mail: yfzhou@ntu.edu.sg 


\section{Contents}

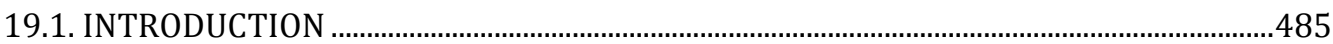

19.2. MECHANISM OF ULTRASOUND-MEDIATED DRUG DELIVERY …...................................487

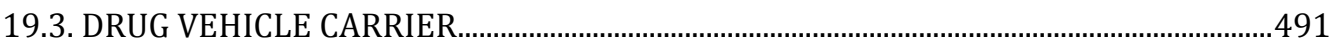

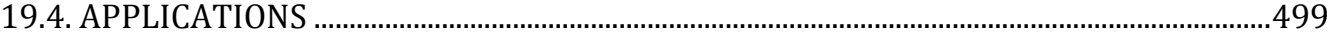

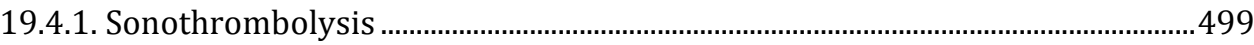

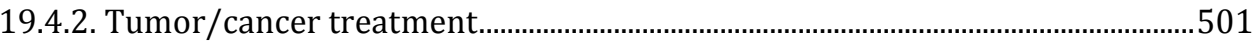

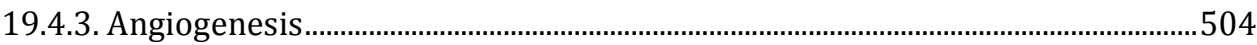

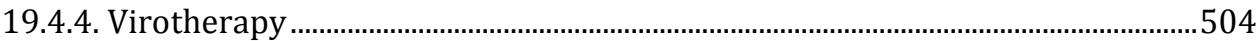

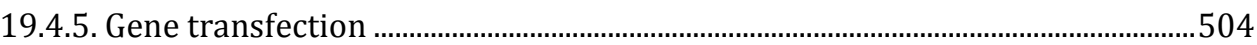

19.4.6. Blood-brain barrier (BBB) disruption ....................................................................507

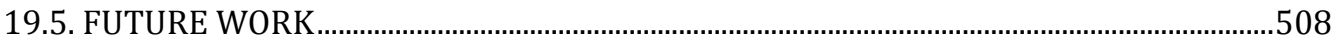

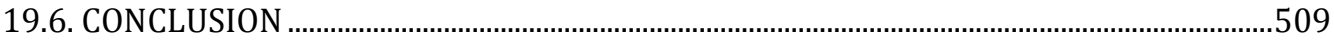

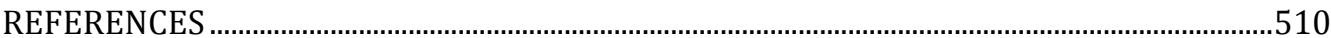




\subsection{INTRODUCTION}

Drug or therapeutic agent delivery to the target is a common problem in medicine. The demand for drug delivery systems in the United States is predicted to have an annual growth rate of more than $10 \%$ and to reach $\$ 132$ billion in 2012 [1]. Nanocarriers accumulate passively within tumors that have a leaky vasculature via the enhanced permeation and retention (EPR) effect [2], and can bind to selected tumor cells through interactions between the vehicle and the target by specific ligands and receptors. Once the carriers have been endocytosed into tumor cells, the release of the drug occurs. Conventional delivery modalities, such as injections and oral administration, have significant advantages in terms of convenience and cost, but have significant limitations. Drugs can be targeted in an either passive or active manner. The major limitation of systemic chemotherapy administration is the exposure of all tissues [3]. Only a small amount of the dose $(<5 \%)$ reached the target (i.e., cancerous, infected or inflamed tissues). Both the structural heterogeneity of biological tissues and the limited accessibility of target cells, which is usually due to an exaggerated desmoplastic reaction, excessive interstitial pressure, and the poor status of the blood vessel endothelium, are detrimental to drug targeting. Therefore, temporally and spatially controlled drug delivery remains an important avenue of research and application.

A "magic bullet" was first proposed by Paul Ehrlich in the early $20^{\text {th }}$ century [4]. To achieve this, great efforts have been made by scientists or physicians to selectively target a disease-causing organism and then deliver therapeutic molecules without damage to healthy tissue in response to a stimulus from an external force or internal microenvironment. The stimulus can be the overexpression of receptors on tumor cells or a physical stimulus such as temperature, $\mathrm{pH}$, light, pressure, ultrasound, electric or magnetic fields. The therapeutic agent should be protected to prevent unintended degradation during its transportation within an organism, concentrate exclusively at the desired site, and then be taken up mostly in the target tissue [5]. Although some nanoparticles have shown promising results in vitro, only a few of them have demonstrated enhanced tumor accumulation and pharmacological efficacy in vivo.

Among all the diagnostic imaging modalities, ultrasound (US) imaging has the unique advantages of real-time data acquisition, low cost, portability, and non-ionization. Since blood has a similar acoustic impedance as that of surrounding soft tissue, it has very low echogenicity. However, the acoustic impedances of most gases are usually six orders of magnitude lower. So, complete reflection occurs at the interface of gas and soft tissue. Microbubblebased ultrasound contrast agents (UCAs) have been developed to improve echogenicity by increasing acoustic scattering and reflection in arteries or 
perfused tissues, especially in cardiosonography. Contrast-enhanced ultrasound (CEUS) has made a significant contribution in clinical diagnosis. Microbubbles must be sufficiently small in order to exit the heart through the pulmonary capillaries and serve as surrogate red blood cells acting as true, non-diffusible, intravascular indicators. A variety of UCAs have been developed and undergone preclinical and clinical trials. Only a few have received Food and Drug Administration (FDA) approval for clinical use. The first approved UCA was Albunex in 1994 for left ventricular opacification [6-8]. Optison (GE Medical Diagnostics) and Definity (Lantheus Medical Imaging) were approved by the FDA in 1997 and 2001, respectively [9]. SonoVue (Bracco Imaging) and Optison have been approved in Europe for clinical diagnosis. Sonazoid (GE Medical Diagnostic) is approved in Japan and Korea [10]. Figure 1 shows an example of nodular peripheral enhancement in a $2.5 \mathrm{~cm}$ hemangioma in the right lobe of the liver using transverse CEUS scan after Sonovue injection. Although unparalleled images of the heterogeneity of tissue perfusion can be provided when intravenously infused UCAs circulate freely throughout the circulatory system [11], CEUS imaging has not yet been able to quantify organ perfusion (i.e., cardiac system, liver, kidney, and brain) [12].
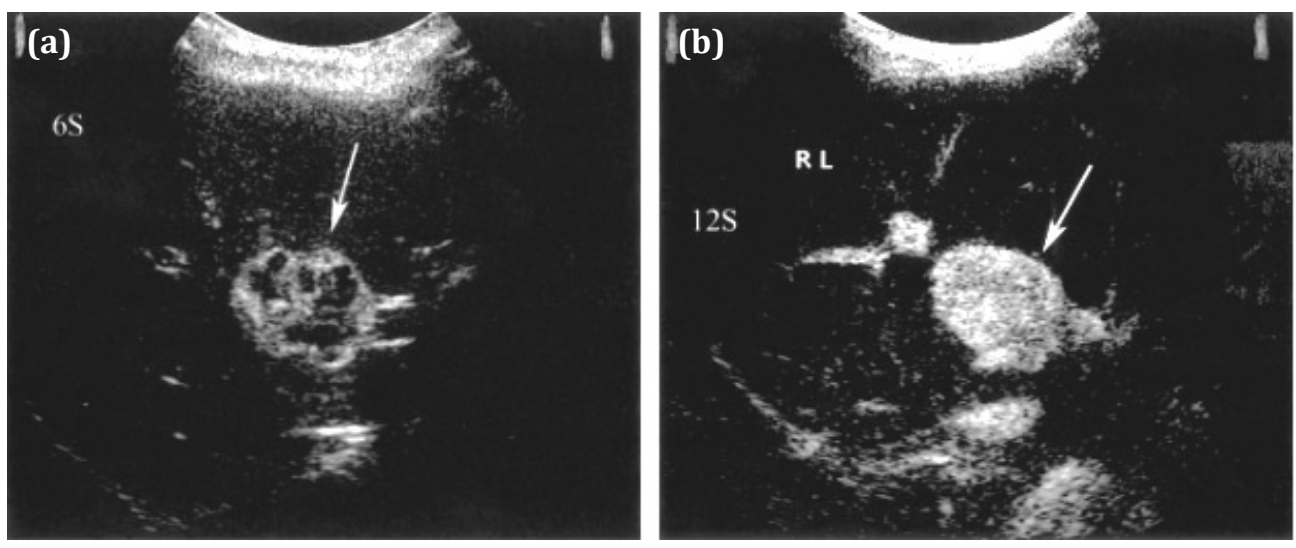

Figure 1. Transverse CEUS scan (a) 6 seconds and (b) 12 seconds after Sonovue injection during the early arterial phase shows nodular peripheral enhancement and very quick centripetal fill-in of the lesion (arrow), respectively, in a 39-year-old woman with a $2.5 \mathrm{~cm}$ hemangioma in the right lobe of the liver, courtesy of [13]

Recently, theranostic technology with concurrent and complementary diagnostic and therapeutic capabilities has become an emerging and promising modality in clinical treatment. Agents are involved to generate signals in response to specific pathological stimuli (i.e., disease diagnosis) and simultaneously release a therapeutic particle (i.e., drug, protein, gene, nucleic acids) to the pinpointed targeted areas. Theranostics may be a revolution in medicine and in the pharmaceutical industry. Ultrasound has been used widely 
in clinics for therapy, such as physiotherapy, hyperthermia, and high-intensity focused ultrasound (HIFU) for tumor ablation. Due to greatly increased interest and the sophistication of imaging and molecular biology techniques, the growth of therapeutic ultrasound is rapid. The first successful application of therapeutic ultrasound in human skin metastases was reported in 1944 [14] despite its first failure on Ehrlich's carcinoma in 1933 [15]. There is now considerable interest in combining ultrasound exposure with microbubbles that act as the vehicle for localized drug delivery [16]. Compared with other approaches, this approach may change the structure of cell membranes and then release encapsulated drugs and molecular mediators (i.e., dextran, pDNA, siRNA, and peptides) into the cytosol upon exposure to ultrasound waves, thus bypassing the degradative endocytotic pathway both in vitro and in vivo [1721]. As a result, the therapeutic index of agents could be increased, and the use of agents with high toxicity or therapeutic inefficiency may be reconsidered and reintroduced. The transformation of microspheres into powerful therapeutic systems by simple application of external acoustic energy has great potential and has attracted a great deal of research interest [22]. Its technical advantages include the use of non-ionizing acoustic waves, with high spatial and temporal resolution, real-time monitoring, affordability, easy operation, portability, wide availability in clinics, and favorable economics.

\subsection{MECHANISM OF ULTRASOUND-MEDIATED DRUG DELIVERY}

The absorption and dissipation of acoustic energy in a medium will cause an elevation in temperature. In soft tissue, ultrasound-induced hyperthermia, at a temperature of $40-45^{\circ} \mathrm{C}$, has been found to decrease DNA synthesis, alter protein synthesis (i.e., heat shock proteins), disrupt the microtubule organizing center, vary expression of receptors and binding of growth factors, and change cell morphology and attachments at the both the subcellular and cellular levels $[23,24]$. Thermo-sensitive drugs can be activated by hyperthermia. Even non-thermosensitive polymeric carriers and drugs exhibit increased localization in heated tumors because of increased tumor blood flow and vascular permeability. Subsequently, the cytotoxicity of the chemotherapeutic agent is enhanced.

Propagation of acoustic waves in the medium results in cyclic bubble compression and expansion and significant energy deposition around the bubbles, as shown in Figure 2. The driving frequency and acoustic pressure amplitude determine the relative contributions of thermal and mechanical mechanisms in the sonication region. The mechanical index (MI) is usually used to describe the possibility of acoustic cavitation [25]. 


$$
M I=\sqrt{\frac{p}{f}}
$$

where $p$ is the peak negative pressure and $f$ is the driving frequency. At a low acoustic amplitude, microbubbles oscillate in a linear manner. Mechanical resonance effects amplify microbubble scattering by an order of magnitude. With an increase of amplitude, significant non-linear responses are evoked. Extraction of the non-linear acoustic response could highlight the signal from microbubbles, which is now available in some sonographic systems. A higher MI (0.3-0.6) causes forced expansion and compression of microbubbles and results in violent bubble collapse [26]. There is less collateral damage to surrounding tissue induced by stable cavitation, while inertial cavitation, using either native or introduced bubbles, may produce significant effects on the extracellular membrane (i.e., permeability) that facilitate drug and gene delivery, generate nanocarrier destabilization (i.e., drug release), directly affect intracellular vesicle morphology, and induce several biological effects to enhance endosomal escape, all leading to the cellular uptake of therapeutic molecules [27]. Acoustic cavitation plays a potentially key role both in achieving targeted and localized drug release and enhanced extravasation at modest output levels, whilst simultaneously enabling real-time monitoring of the drug delivery process. However, $0.5-2.5 \mathrm{MHz}$ ultrasound with up to 2.0 MPa pressure alone showed no significant difference in cell viability [28].

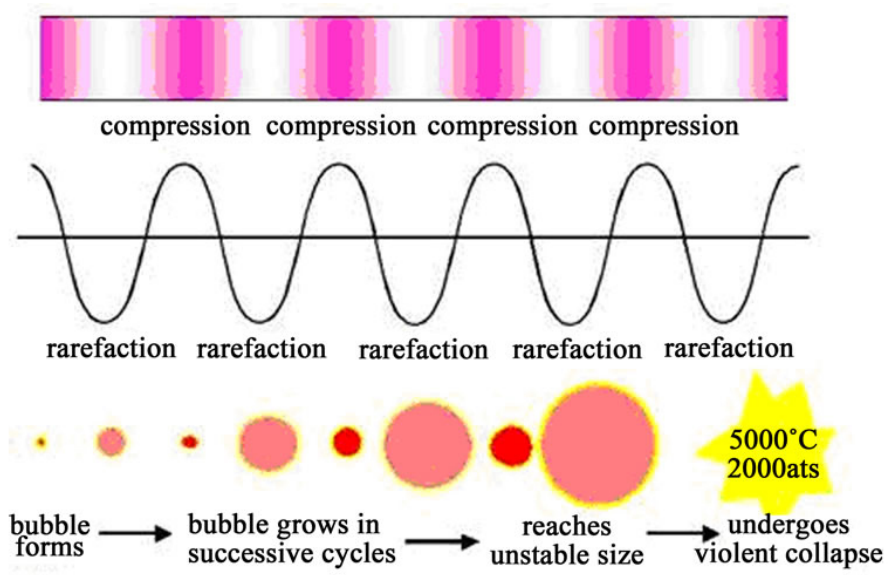

Figure 2. Schematic diagram of oscillation and collapse of bubble in the acoustic field, which is termed as acoustic cavitation phenomenon

Meanwhile, ultrasound may also increase the convection of liquid by acoustic streaming in the direction of sound propagation $[29,30]$ or microstreaming 
and shear flow due to stable or inertial cavitation of oscillating bubbles (i.e., repeated expansion and shrinkage) [30,31]. Both of them may increase microvascular leakage and enhance drug delivery by extravasation.

If inertial cavitation occurs in proximity to the target cell, transient pores may be formed in the cell plasma membrane, as shown in Figure 3, which offers an efficient way for intracellular uptake of a drug/gene via enhanced membrane permeability or endocytosis, although its transfection efficacy is not so high as with viral vectors, and the time window is limited [32,33]. Those relatively small pores (from tens to hundreds of nanometers) will seal by energy- and calcium-dependent repair within a few minutes [33-35]. Otherwise, cell viability may not be maintained. Microbubbles serving as cavitation nuclei greatly enhance sonoporation. The concentration of microbubbles at a target site needs to be optimized; too high a concentration poses the potential risk of embolism and may also produce an excessive acoustic shielding effect, preventing exposure of the target tissue. In order to avoid irreversible membrane disruption and a disrupted cell cycle and consequently significantly reduced detrimental cellular bio-effects [36], a series of relatively short ultrasound pulses are generally delivered. The thresholds of inertial cavitation depend on the shell elasticity of microbubble. Thus, sonoporation may ultimately be most effective in promoting the extravasation of large macromolecules to improve delivery to tissue beyond the vasculature [37-40]. Sonoporating the tissue first and then releasing the nanoparticle before the pores on the cell membrane reseal may be advantageous. Sonoporation is suited for site-specific drug delivery by controlling ultrasound exposure under the guidance of a certain imaging modalities.
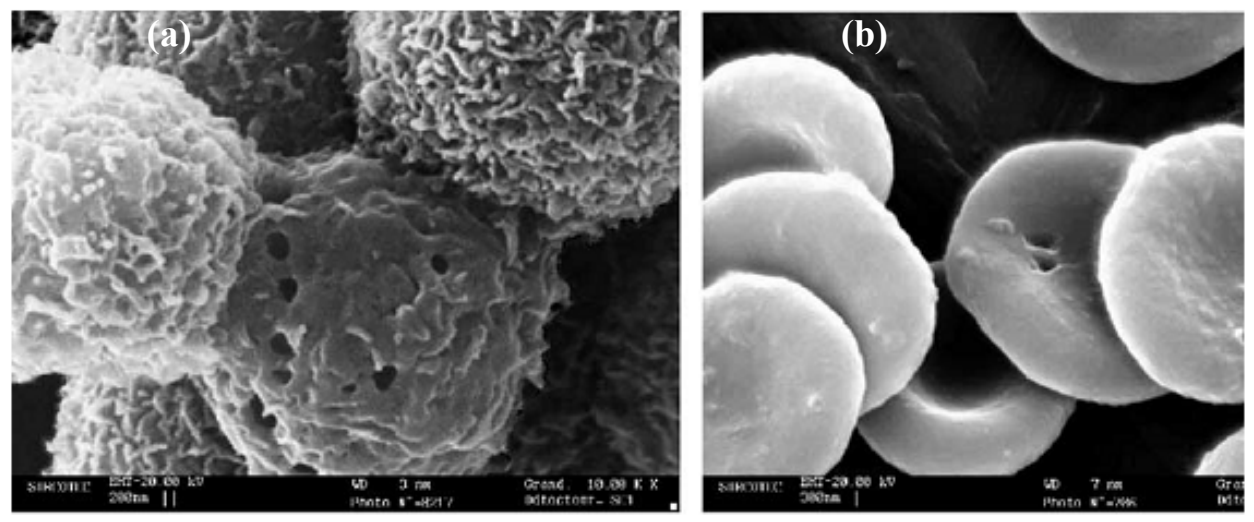

Figure 3. Representative pores at (a) MAT B III and (b) red blood cells after sonication in the presence of microbubbles illustrated by scanning electron microscope, courtesy of [41]

One of the major obstacles to non-viral gene delivery is nuclear entry. Passive diffusion of macromolecules in the cytoplasm is restricted by the complex 
network of microtubules, proteins, and various subcellular organelles. For non-dividing cells, molecules larger than $40 \mathrm{kDa}$ are actively transported into the nucleus through a nuclear pore complex. In contrast to plasmid DNA delivery, inefficient RNA interference (RNAi) is preferred in the transnuclear localization of siRNA since siRNA acts in the cytosol.

In addition to membrane channel transport, endocytosis, an energy-requiring process by which cells absorb molecules by engulfing them, also plays an important role [36,42]. The induction of surface pores or depressions may enhance the effectiveness of endocytosis; the process is illustrated in Figure 4. Increased local hyperpolarization, endocytosis, and pinocytosis of the cell membrane favor the absorption of macromolecular substances in the size range of $70-500 \mathrm{kDa}[43]$.

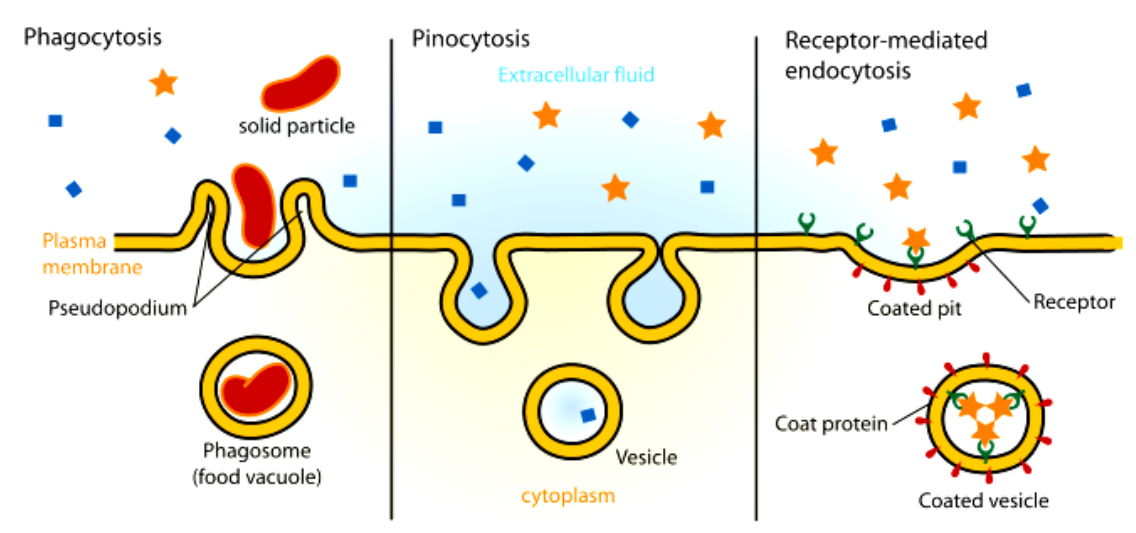

Figure 4. Schematic diagram of different types of endocytosis

Apoptosis (programmed cell death) is the initiative programmed death of gene-controlled cells under physiological or pathological conditions, as shown in Figure 5, This may occur in the developmental process of tissues and organs, or in stressed cells to get rid of irreversible damage or harmful cells (i.e., malignant tumors). Molecular pathways of cell apoptosis are influenced by an array of stimuli, such as the lack of cell growth factors, ionizing radiation, DNA damage, immunoreactions, ischemic injury, anti-hormonal therapy, and the expression of genes and the intracellular distribution of a cytotoxic agent. Most apoptotic pathways involve aspartate-specific cysteine protease family members (the caspases), cell senescence, pyroptosis, and poly(ADP-ribose) polymerase-1 (PARP-1)-mediated cell death. Sonoporation may lead to apoptosis and cell cycle arrest to suppress cancer cell growth. With plasmid transfection and ultrasound irradiation, the apoptosis rate is about $13 \%$; the apoptosis rate with ultrasound targeted microbubble destruction (UTMD) is $43.86 \% \pm 4.44 \%[44]$. 


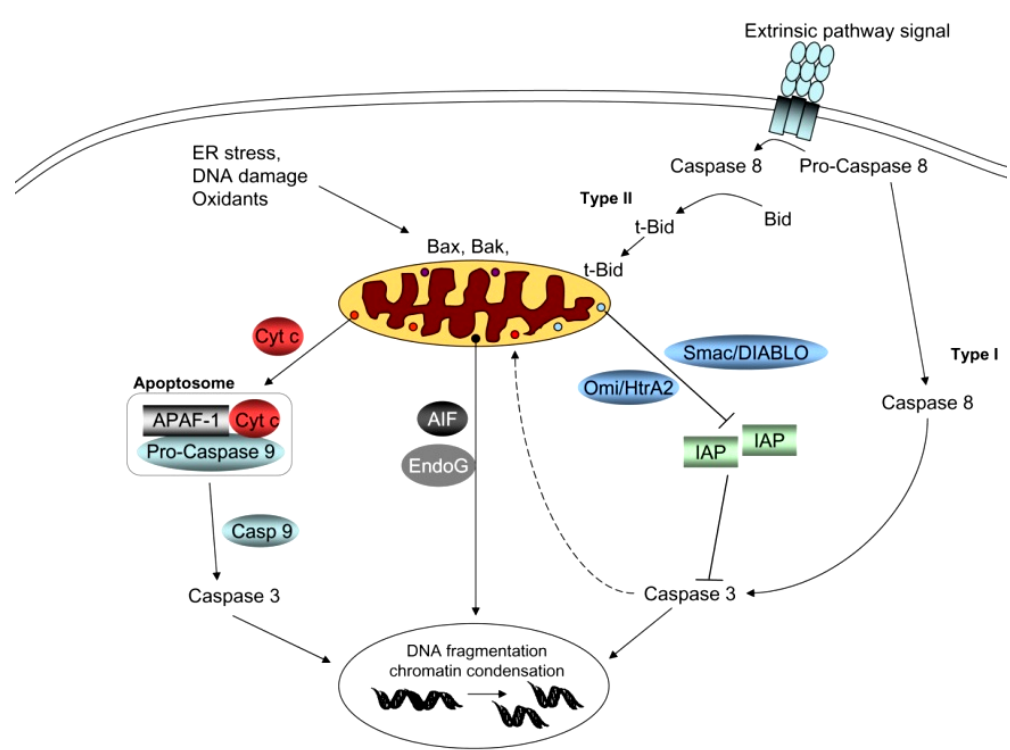

Figure 5. The pathways of apoptosis, courtesy of [45]

The use of light for therapy began in 1900, combining acridine orange and light to destroy a paramecium [46]. The cytotoxic product of the photochemical reaction of non-porphyrin photosensitizers was identified to be singlet oxygen [47]. The terminology of sonodynamic therapy, which combines ultrasound with a sonosensitive agent derived from chlorophyll, appears contextually aligned with photodynamic therapy. The use of ultrasound is more complicated than using light because it can potentially produce free radicals and light (sonoluminescence) during acoustic cavitation. The agents themselves have no antitumor ability, but exhibit it only in the context of sonochemistry. Therefore, much less risk of adverse effects is expected for normal tissues.

\subsection{DRUG VEHICLE CARRIER}

Contrast agents (Echovist ${ }^{\circledR}$, agitated saline containing air bubbles) were first used in in 1968 for echocardiography; improved aortic delineation was reported. However, large air bubbles disappeared within a few seconds following intravenous injection due to the high solubility of air in the blood, and the inability of the bubbles to pass through pulmonary capillaries. With continued interest and technological advances in CEUS, efforts have been made in the design and manufacturing of microbubble contrast agents, especially in terms of their clinical safety, stability, and size. The second generation of microbubbles have been developed, using high molecular weight hydrophobic and poorly diffusive gases (i.e., perfluorocarbons, perfluorobutane, and sulfur 
hexafluoride) surrounded by a thin and stabilizing shell composed of phospholipids and biocompatible and biodegradable polymers (i.e., pLGA), proteins, or surfactant molecules [48,49]. Longer-chain lipids with a higher phase transition temperature can improve the stability of microbubbles. The circulation half-life of Optison ${ }^{\circledR}$ and SonoVue ${ }^{\circledR}$ is more than 15 minutes $[50,51]$. Such microbubbles can circulate a few times after injection. The microbubbles $(0.5-8 \mu \mathrm{m}$ in size) have resonance frequencies within the range of a sonographic system $(0.2-15 \mathrm{MHz})$. If microbubbles are less than $0.5 \mu \mathrm{m}$ in diameter, there is no significant contrast effect at clinical concentrations. Enhancing cross-linking and/or chain entanglement in the shell, such as by using synthetic polymers, further enhances the stability of microbubbles, but reduces the elasticity of the shell and attenuates their oscillation patterns.

The simplest way of enhancing drug delivery by ultrasound is to introduce microbubbles and the therapeutic agent of interest simultaneously. For example, blood clots could be dissolved more quickly for decanalization in stroke patients under ultrasonic exposure in the presence of microbubbles and tissue plasminogen activator (tPa) or urokinase. However, transfection is poor if the target is not in the circulatory system.

The various physicochemical properties of microbubbles allow for a variety of bioactive substances (i.e., genes, drugs, proteins, antisense constructs, gene silencing constructs, and stem cells) to be attached to or incorporated in order to increase the ability to be effectively and specifically introduced into different targets. There are various ways of entrapping drugs within a microbubble (see Figure 6) [52,53]. Drugs may be incorporated into the membrane or in a shell of microbubbles. A monolayer lipid shell (2-3 nm for phospholipid microbubbles) limits loading the hydrophobic pharmaceuticals, and may lead to a premature release [54]. Although a thicker triglyceride lipid shell can increase the loading capacity, it is only available for hydrophobic drugs (i.e., paclitaxel). Polymeric microbubbles have a much higher loading capacity of both hydrophobic and hydrophilic drugs; the release rate depends on the drug properties (i.e., lipophilicity and water solubility). Negatively charged drugs can have stable and strong deposition in or onto a cationic microbubble shell by electrostatic interactions. However, Küppfer cells, leukocytes, and macrophages may capture these charged microbubbles. Because of the short half-life, UTMD has mainly focused on to the cardiovascular system, the central nervous system, and tumor endothelium. Multiple drug reservoirs (i.e., nanoparticles encapsulated with different types of therapeutics) can attach to the microbubble surface or be enclosed within the microbubble. 


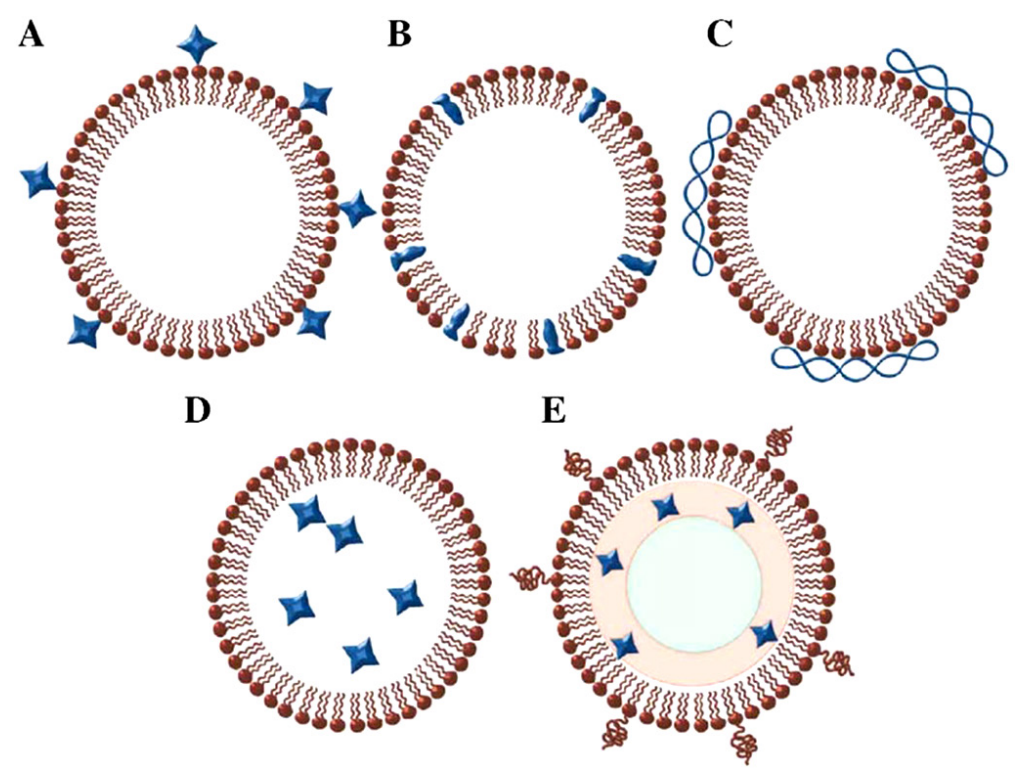

Figure 6. Different approaches to loading drugs/DNA into microbubbles by (A) attaching to the membrane, (B) embedding within the membrane, (C) bounding non-covalently to the surface, (D) enclosing inside, and (E) incorporating into an oily film surrounded by a stabilizing layer with a ligand for targeting, courtesy of [55]

Nucleic acids are rapidly degraded in a biological environment. Deposition methods for nucleic acids include direct incorporation of the DNA into the microbubble shell [56], the use of cationic lipids in the microbubble shell [32], deposition of single [57] or multiple layers [58] of cationic polymers on the microbubble shell, covalent linking of DNA-nanoparticle carriers [59], and the use of complementary DNA strands to load nanoparticles. The drawbacks of incorporated naked plasmid DNA (pDNA) and pDNA-polymer complexes released from microbubbles are the large microbubble size $(3-7 \mu \mathrm{m}$ with a consequently short circulation time and ineffective extravasation into the tumor); the necessity to complex pDNA with cationic polymers to prevent degradation; the low loading efficiency of pDNA ( $\sim 6700$ molecules/bubble) due to the limited number of cationic lipids; and premature release of more than $20 \%$ of the encapsulated pDNA [60]. pDNA and siRNA have been covalently bound via biotin-avidin-biotin linkages to the microbubble shell. The capacity of a $3 \mu \mathrm{m}$ bubble is more than 12,000 DNA molecules.

pDNA is bound to cationic lipid shelled microbubbles via electrostatic charge coupling [61,62]. Mixing a cationic lipid in the aqueous phase with other lipid components uniformly is a simple method of preparation. Such electrostatic interactions are controlled by the ionic strength of the incubation media, the concentrations of the reactants, and their order of mixing. The much smaller size and lower cationic charge of the resulting polyplexes facilitate cellular 
uptake. However, aggregation between cationic polyplexes and anionic blood proteins (i.e., albumin) leads to rapid clearance by the reticuloendothelial system (RES). Immature decomplexation of cationic polymers and anionic nucleic acids occurs because of the high ionic strength of the blood.

The cationic polymer polyethylenimine (PEI) has high cationic charge, which enables the polymer to bind and condense DNA, as well as inhibit enzymatic degradation, prolong the in vivo lifetime, promote endocytosis for cellular uptake, facilitate endosomal escape of DNA into the cytoplasm, and enhance the degradation of nucleic acids by acid activated enzymes in the cytoplasm. After crossing the membrane, PEI can induce osmotic swelling and trigger the release of DNA [63]. PEI-based vectors are rapidly cleared by the RES and are cytotoxic in high doses. Ameliorating the surface charge by adding non-ionic polyethylene glycol (PEG) can significantly improve their performance. Covalently coupling PEI polymers to the lipid microbubble shells via PEG-tethered maleimide groups (PEI-PEG-SH) creates polyplex-microbubble hybrids [64]. PEI and DNA loading into microbubbles can be controlled by modulating the maleimide concentration in the microbubble shell. Ex vivo studies on excised tumors have shown 40 -fold higher expression, while a 10-fold increase was found in vivo [65-67].

Anionic bubble lipopolyplexes, 450-600 $\mathrm{nm}$ in diameter, deliver pDNA into cells without endocytosis and lead to high gene expression in liver non-parenchymal cells following US exposure. In addition, anionic bubble lipopolyplexes do not show any severe hepatic toxicity and do not enhance the production of proinflammatory cytokines. Because of their neutral electric charge, anionic bubble lipopolyplexes can be prepared without aggregation even under high concentration conditions.

In order to selectively adhere microbubbles to cellular epitopes and receptors of target cells and subsequently increase drug delivery specificity and transfection, one or several specific ligands, such as antibodies, carbohydrates, and peptides, are coupled to the shell (see Figure 7) [68]. Monoclonal antibodies have a very high specificity and selectivity for a large range of epitopes. In contrast, peptides are low-cost and less immunogenic. Simultaneous targeting to multiple ligands could synergistically increase adhesion strength [69]. There are two ways of coupling ligands to the microbubble shell: covalent binding by being attached to the head of phospholipids directly or via an extended polymer spacer arm and non-covalent binding by avidin-biotin bridging and streptavidin-biotin bonding. However, since avidin carries a strong positive charge in the glycosylate layer, the bio-distribution of microbubbles may be altered, resulting in non-specific adhesion and initiation of an undesired immune response. Furthermore, several washing steps required in the loading process influence microbubble stability and reproducibility. In comparison, streptavidin may be a better alternative. Using a PEG molecular tether as an intermediary spacer arm between the ligand and the lipid shell indirectly is 
feasible and results in high specificity and targeting. Folate receptors are expressed in in large numbers on many cancer cells. Folate that is attached to a PEG tether may undergo enhanced interaction with receptors on the cell membrane, leading to intracellular uptake.

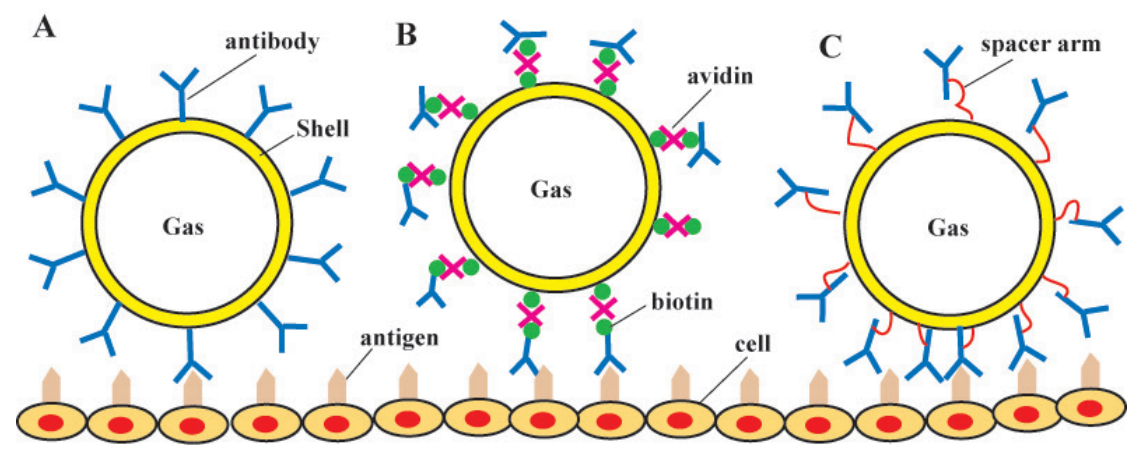

Figure 7. Targeting microbubbles to cancer cells by connecting the receptors on the surface with (A) an antibody, (B) an avidin bridge, or (C) a flexible spacer arm, courtesy of [70]

Magnetic microbubbles have been developed which are capable of carrying a drug payload and can be moved to the target site by means of an external magnetic field gradient under the guidance of magnetic resonance imaging (MRI); these are then disrupted by a focused ultrasound beam $[3,71,72]$. Superparamagnetic materials are used to build to the shell because of a compromise between strong magnetization and avoidance of particle aggregation [73]. Superparamagnetic iron oxide nanoparticles SPION loaded bubbles have been shown to improve the contrast of both ultrasound and MR images [74]. A mixture of non-magnetic microbubbles and magnetic micelles (containing magnetic nanoparticles but no gas) have in fact shown slightly higher transfection efficiency upon exposure to both ultrasound and a magnetic field. In an alternating magnetic field (AMF), heat will be generated in magnetic nanoparticles because of hysteresis loss and/or Neel relaxation. These effects alter the nanocarrier structure, i.e. by increasing the shell or bilayer porosity, disintegrating the $\mathrm{Fe}_{3} \mathrm{O}_{4}$ core, or deforming the single-crystal nanoshell lattice, leading to pulsatile drug release on demand. However, magnetic guidance is hampered by the complexity of the set-up and the high strength and gradient of the magnetic field that needs to be applied against the hydrodynamic forces of blood flow [75].

However, the accessibility of microbubbles is restricted because of their size through vasculature barriers. Advances in nanotechnology could benefit drug and gene delivery, since nano-sized carriers $(<500 \mathrm{~nm})$ are optimal for 
extravasation into the tumor interstitial space, passing through cell membranes, and delivering both small molecules and macromolecules [76].

Liposomes, made by hydrating a dry lyophilized precursor matrix, have pockets of entrapped air within the lipid bilayer of the liposome membrane and can deliver both hydrophilic and hydrophobic drugs and larger molecules (i.e., pDNA, siRNA, and mRNA) by an ultrasound trigger [77,78]. A significant merit of nanoparticles over microbubbles is their small size (usually $<250 \mathrm{~nm}$ in diameter) and PEG coating, which allow them to circulate in the bloodstream for hours and then extravasate in tumors, ischemic cardiac tissue, and skeletal muscle [50].

Thermosensitive liposomes (TSLs) were first synthesized in 1980 to treat solid L1210 xenograft tumors in mice [79], but it was found that therapeutic ultrasound can serve as a source of hyperthermia and trigger doxorubicin (DOX) release [80]. Such a thermal response arises from a phase transition of the constituent lipids and conformational variations in the lipid bilayer at around $40{ }^{\circ} \mathrm{C}$ (see Figure 8). These are the most advanced thermoresponsive nanosystems and have been used in several clinical trials [81,82]. TSLs can be mixed with microbubbles to synergize both the thermal and cavitational mechanisms (cavitation and radiation force) induced by ultrasound $[83,84]$.

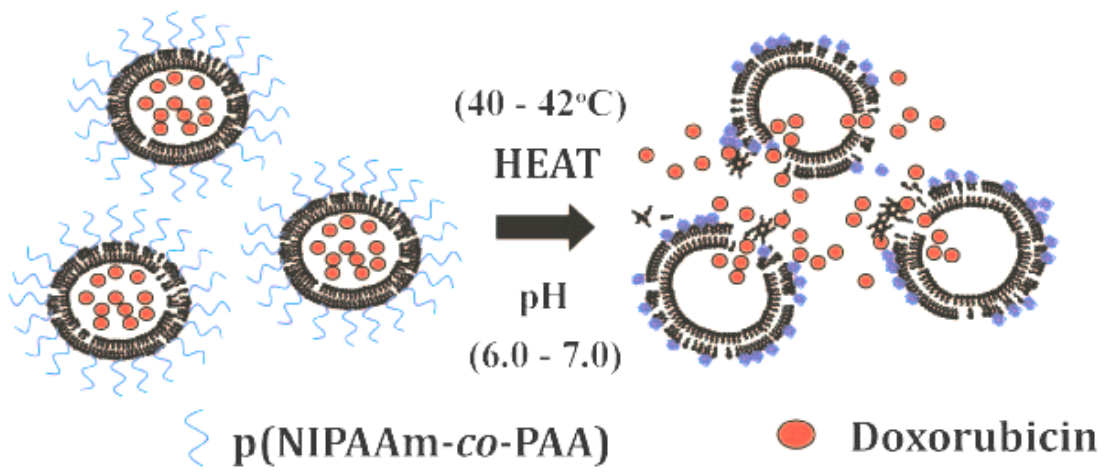

Figure 8. Release of doxorubicin from temperature-sensitive liposomes at their phase transition temperature, which is typically chosen to be $40-42{ }^{\circ} \mathrm{C}$

Conjugating liposomes loaded with both hydrophilic and hydrophobic drugs to a microbubble shell via avidin-biotin interactions, as shown in Figure 9, combines the advantages of liposomes and microbubbles and overcomes their respective individual limitations $[85,86] ; \sim 10^{5}$ liposomes can be bound to each microbubble. This $1.5 \mu \mathrm{m}$ liposome-microbubble hybrid oscillates in a similar manner to unconjugated microbubbles. After disruption of the microbubble, the liposomes are detached. Positively charged lipoplexes or polyplexes can be placed on the surface of the microbubbles using a similar approach $[59,87]$. 
The FDA-approved liposomal drugs are listed in Table 1, while there are many more drugs still at the stage of clinical trials $[88,89]$.

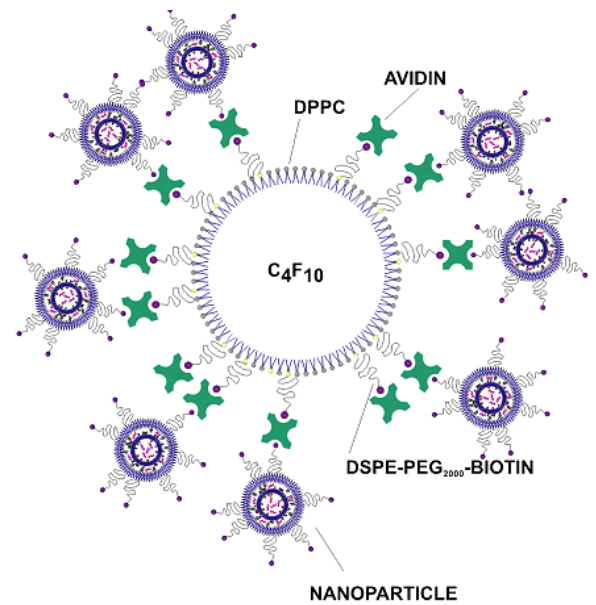

Figure 9. Schematic diagram of PEGylated nanoparticles attached to a microbubble via avidin-biotin binding, courtesy of [90]

Table 1. Liposomal drugs approved for clinical use, courtesy of [88,89]

\begin{tabular}{ccc}
\hline Product & Drug & Approved indication \\
\hline Ambisome & Amphotericin B & Severe fungal infections leishmaniasis \\
\hline Abelcet & Amphotericin B & Severe fungal infections \\
\hline Amphotec & Amphotericin B & Severe fungal infections \\
\hline DaunoXome & Daunorubicin & Kaposi's sarcoma \\
\hline Doxil/Caelyx & Doxorubicin & $\begin{array}{c}\text { Kaposi's sarcoma, ovarian/breast cancer, } \\
\text { multiple myeloma+Velcade }\end{array}$ \\
\hline Lipo-Dox & Doxorubicin & Kaposi's sarcoma, ovarian/breast cancer \\
\hline Myocet & Doxorubicin & $\begin{array}{c}\text { Combination therapy with } \\
\text { cyclophosphamide in metastatic breast } \\
\text { cancer }\end{array}$ \\
\hline Visudyne & Verteporphin & $\begin{array}{c}\text { Age-related molecular degeneration, } \\
\text { pathologic myopia, ocular histoplasmosis }\end{array}$ \\
\hline Depocyt & Cytarabine & Neoplastic meningitis and lymphomatous \\
& meningitis
\end{tabular}


(continued) Table 1. Liposomal drugs approved for clinical use, courtesy of $[88,89]$

\begin{tabular}{ccc}
\hline Product & Drug & Approved indication \\
\hline Expaxal & $\begin{array}{c}\text { Inactivated hepatitis A } \\
\text { virus (stain RG-SB) }\end{array}$ & Hepatitis A \\
\hline Inflexal V & $\begin{array}{c}\text { Inactivated } \\
\text { hemagglutinin of } \\
\text { influenza virus strains A } \\
\text { and B }\end{array}$ & Influenza \\
\hline
\end{tabular}

Alternatively, microbubbles $(1-5 \mu \mathrm{m})$ can be formed in situ from a small liquid emulsion droplet (200-300 $\mathrm{nm}$ ) by acoustic droplet vaporization (ADV) using ultrasound frequencies above $1 \mathrm{MHz}$ applied in microsecond-length pulses [91-93]. Perfluorocarbon droplets have a low boiling point and high stability. The Laplace pressure imposed upon the emulsion droplets due to their high curvature is given by:

$$
\Delta p=p_{\text {in }}-p_{\text {out }}=\frac{2 \gamma}{R_{\mathrm{e}}}
$$

where $p_{\text {in }}$ and $p_{\text {out }}$ are the pressures inside and outside the droplet, respectively, $\gamma$ is the surface tension, and $R_{\mathrm{e}}$ is the radius of the droplet. When the temperature is above the boiling point of PFC5 $\left(29^{\circ} \mathrm{C}\right)$, the vapor pressure is lower than the internal pressure of the nanoemulsion droplet, so the droplet remains in the liquid state.

PEG-modified liposomes entrap nanodroplets in the size range of $600-700 \mathrm{~nm}$ and are termed bubble liposomes. The preparation of bubble-liposomes is quite simple: existing aqueous liposomes are placed in a vial with pressurized perfluoropropane gas, and the vial is sonicated in a bath for several minutes. Perfluoropropane inside bubble liposomes may be in the liquid form in the size range of several tens of nanometers and be subjected to excessive Laplace pressure. Liquefied superheated perfluoropropane droplets can be triggered by ultrasound to become much larger gas bubbles; this releases the liposome contents, as shown in Figure 10 [94,92]. Although cationic liposomes often cause the agglutination of erythrocytes and high levels of hemolysis due to the interaction between the lipid and the erythrocyte membrane, bubble liposomes containing cationic lipids have little effect on erythrocytes [95]. The loading of pDNA onto the surface of bubble liposomes (30-40\%) containing cationic lipids, by either electrostatic interactions or the fixed aqueous layer formed with PEG, provide effective protection of pDNA against serum, resulting in high transfection efficiency due to the retention of the pDNA-supercoiled structure [96]. Furthermore, adding pDNA to bubble liposomes does not result in a significant change in the physical properties. 


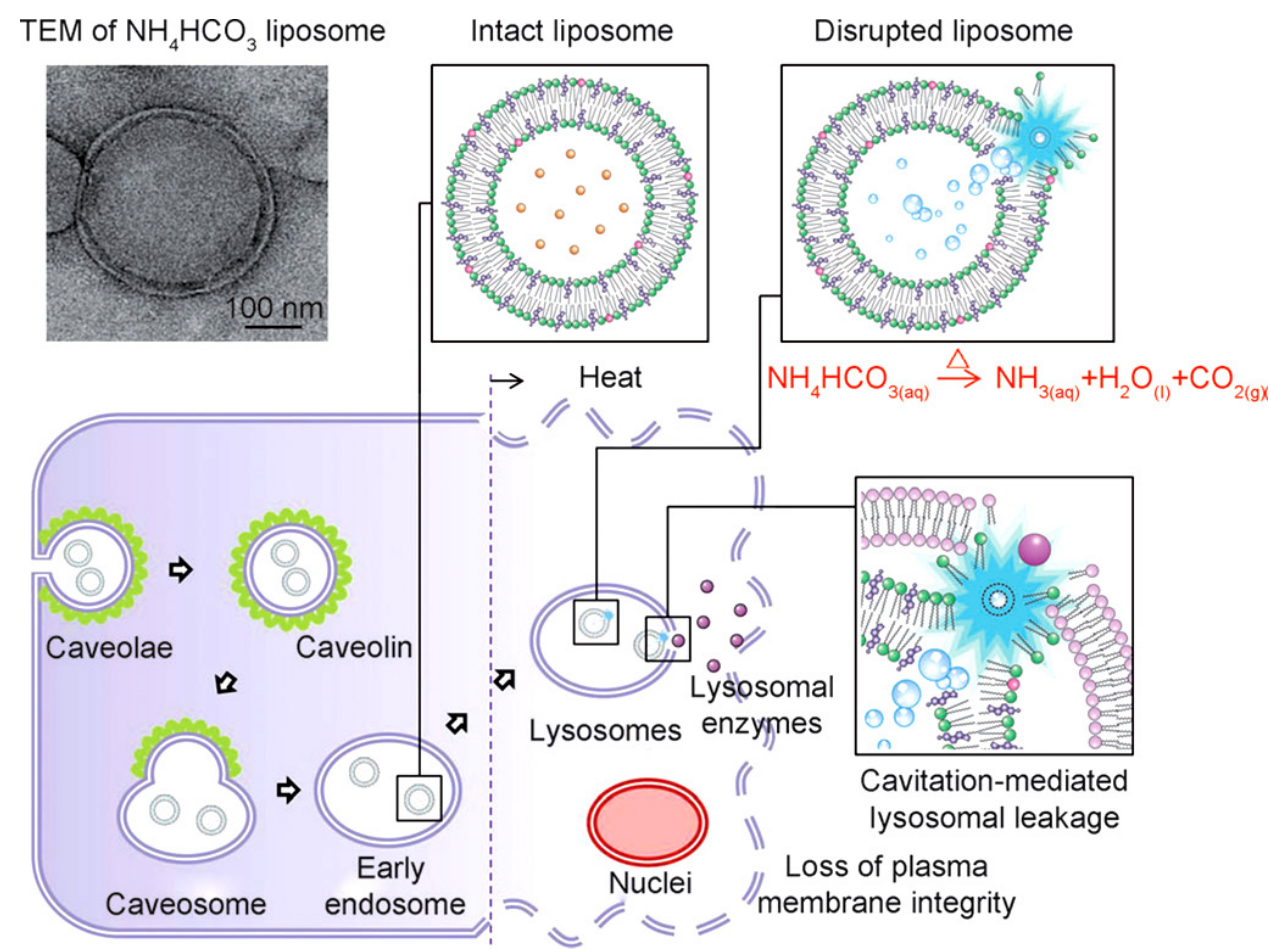

Figure 10. A schematic illustration showing the composition/structure of liposomes that generate bubbles upon heating, and how they can be used to rupture cancer cells by transient cavitation, thus resulting in cell death, courtesy of [97]

eLiposomes are similar to bubble liposomes, as they encapsulate emulsions and therapeutic agent in liposomes for targeted delivery. Phase transition of emulsion droplets ruptures the lipid bilayer of the eLiposome to release the therapeutic agent after sonication. To prepare eLiposomes, a plasmid and lipid-stabilized perfluoropentane nanoemulsion is co-entrapped in carrier liposomes. There are no cationic eLiposome components and or toxic molecules in this formulation.

\subsection{APPLICATIONS}

\subsubsection{Sonothrombolysis}

Clot formation within a vessel in the brain causes ischemic stroke, within the coronary arteries causes myocardial infarction, and within the peripheral veins causes deep vein thrombosis. Acute ischemic stroke occurs frequently worldwide and is the third leading cause of death. The dissolution and breaking up of a clot using thrombolytic drugs, such as tissue plasminogen activator (tPA), could limit the damage caused by the blockage of blood vessels, 
and is termed thrombolysis. Currently, the only FDA-approved therapy for acute ischemic stroke is intravenous (IV) administration of rt-PA within $3 \mathrm{~h}$ of stroke onset. In order to improve the clinical efficacy of thrombolysis, ultrasound has been investigated in combination with thrombolytic drugs to enhance recanalization by creating high-speed microjets during the asymmetric collapse of microbubbles [98]. The process is illustrated in Figure 11.
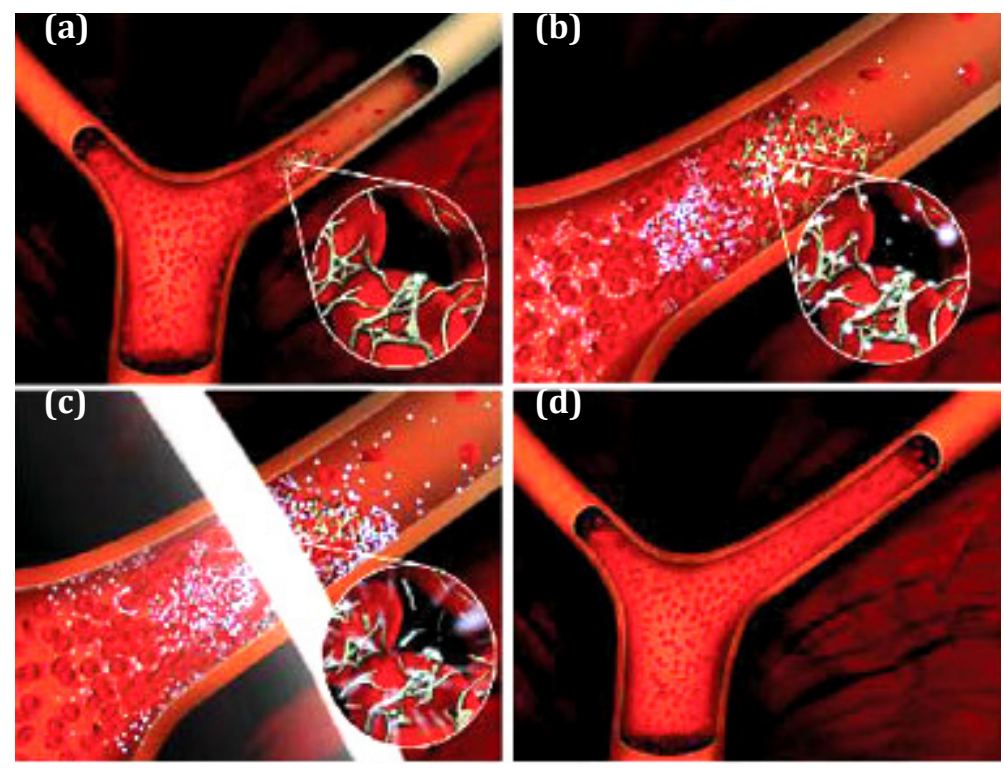

Figure 11. An illustration of sonothrombolysis process: (a) an intracranial occlusion, (b) microspheres reach the site of the intracranial occlusion and permeate around or through the thrombus, (c) an ultrasound pressure wave oscillates and destroys the microspheres, leading to (d) complete arterial recanalization, courtesy of [99]

Two clinical trials have investigated sonothrombolysis. The Combined Lysis of Thrombus in Brain Ischemia Using Transcranial Ultrasound and Systemic t-PA (CLOTBUST) trial used $2 \mathrm{MHz}$ ultrasound at an intensity of $750 \mathrm{~mW} \mathrm{~cm}^{-2}$ with a sample volume of 3-6 mm for power Doppler and 10-15 mm for transcranial Doppler (TCD), respectively [100]. Early and complete recanalization of the arterial occlusion was more significant in the group exposed to continuous TCD than the control ( $46 \%$ vs. $18 \%$ within $2 \mathrm{~h}, p<0.001$ ), and both clinical recovery and complete recanalization were $25 \%$ vs. $8 \%(p=0.02)$. In addition, both groups had similar rates of intracranial hemorrhage. The other trial was the Transcranial Ultrasound in Clinical Sonothrombolysis (TUCSON) trial using perflutren lipid microspheres [99]. Microbubbles decreased the time to arterial recanalization and increased the rate of recanalization. Low doses of microbubbles used in sonothrombolysis may be safe, but higher doses 
increased the rate of symptomatic intracranial hemorrhage (SICH) [101]. Furthermore, reverberations of the low frequency ultrasound (i.e., $120 \mathrm{kHz}$ ) inside the skull lead to hot spots of energy and more SICH [102].

Targeted Arg-Gly-Asp-Ser tetrapeptide (RGDS) microbubbles prepared by lyophilization have also been prepared to encapsulate t-PA [103]. The envelopment rate of tPA was $81.12 \pm 2.44 \%$, detected by enzyme-linked immunosorbent assay (ELISA). The conjugation rate of RGDS was $94.49 \pm 6.19 \%$, detected by flow cytometry. In addition, sonothrombolysis using intermittent high MI pulses guided by a 3-D sonography is effective at improving myocardial blood flow and decreasing infarct size [104]. Upstream pressure decreased progressively during US delivery, indicating the thrombolysis process. More rapid and complete lysis occurred with increasing peak negative acoustic pressure (1.5 $\mathrm{MPa}$ vs. $0.6 \mathrm{MPa})$ and increasing pulse length (5000 cycles vs. 100 cycles).

\subsubsection{Tumor/cancer treatment}

Tumor tissues have atypical microvascular permeability, leading to the enhanced permeability and retention (EPR) effect, which enhances passive drug targeting. However, the larger amount of collagen in the tumor extracellular matrix might require a higher infusion pressure to initiate the flow of medicine or a gene into the tumor mesenchyme. UTMD is a promising new method and has the advantages of non or minimal invasiveness, high gene and drug transfer efficiency, and high organ and tissue specificity [105]. It can change the tumor microenvironment and provide felicitous conditions to achieve even and sufficient drug delivery effectively [106]. Whilst there is a concern that ultrasound-induced inertial cavitation may create shear forces that induce the breakup of primary cancer cells, thereby enhancing metastasis, this has been recently assuaged. It was found that there was no difference in the observed metastases between control and ultrasound-treated xenograft mice [107]. This conclusion is also valid in human patients, as no increased chance of metastasis has been reported [108]. Tissue with thick veins could be transfected with US exposure, given enough time when the mixture of pDNA and bubble liposomes is injected. In contrast, nanosized pDNA loaded bubble liposomes (p-BLs) are a potentially superior carrier during transfection via microvessels or transfection into tissues with low blood flow to deliver various negatively charged molecules [109].

In human cancers, malignant cells possess defects in apoptosis that increase their resistance to anti-tumor treatment; this plays a critical role in tumorigenesis. Ultrasound irradiation has been shown to induce apoptosis in tumor cells. A significant reduction in tumor size was observed using cisplatin and cetuximab-coupled microbubbles in immune deficient mice with xenografts; the subsequent histological study illustrated increased numbers of apoptotic cells following UTMD compared with chemotherapeutic agents 
alone. The induction of apoptosis mediated by UTMD is safer and more effective than other methods, by inactivating tumor cells, restraining cell proliferation, and improving the therapeutic effects of genes or chemotherapeutic drugs.

Multidrug resistance (MDR) is a major barrier to chemotherapy and is responsible for the overall poor efficacy of drug therapies. It is mediated by the overactivity of several MDR-associated proteins and P-glycoproteins. UTMD may significantly decrease P-glycoprotein and MDR-associated protein expression at the mRNA level rather than increase the sensitivity of MDR cells to sonoporation. Thus, ultrasound exposure could be used as an alternative, physical method to reverse MDR in cancer cells [110].

Doxorubicin loaded TSLs (ThermoDox, Celsion Corporation) have been assessed in phase II trials for the treatment of breast cancer and colorectal liver metastasis, and in phase III trials for the treatment of hepatocellular carcinoma in association with hyperthermia or radiofrequency ablation. An example of spheroid viability in vitro after treatment with TSLs and ultrasound is shown in Figure 12.

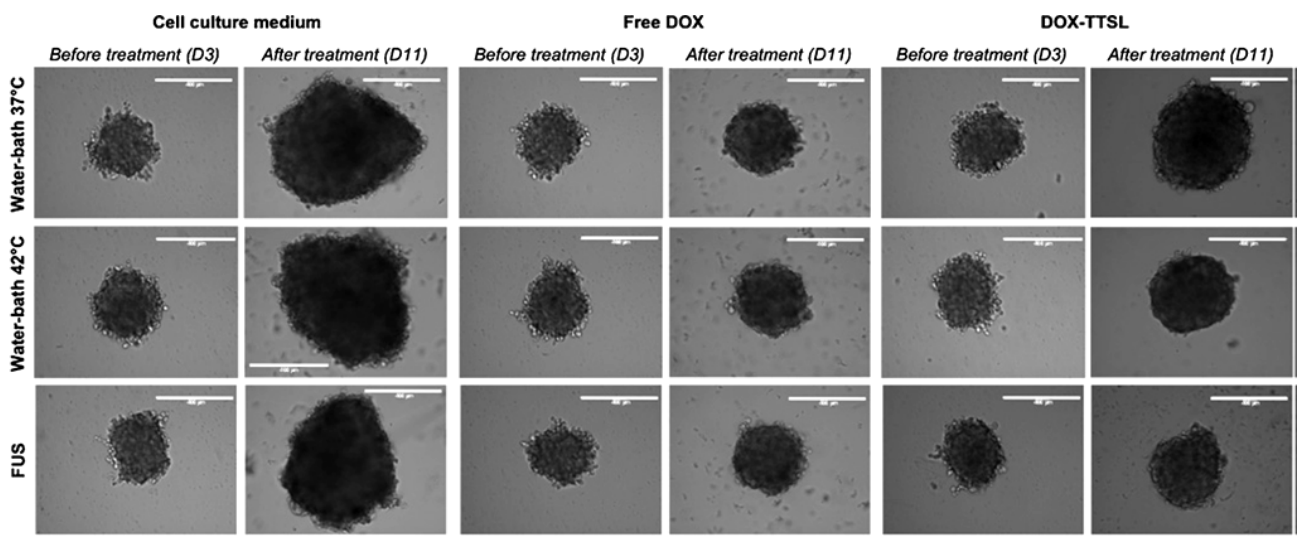

Figure 12. Microscopic observations of U-87 MG spheroids after treatment with TSLs and focused ultrasound (FUS) mediated hyperthermia, courtesy of [111]

Sonoporation and microbubbles were first utilized in clinics for local therapeutic delivery in 2013 [112]. Five patients with inoperable pancreatic cancer were administered gemcitabine followed by sequential doses of microbubbles and ultrasound within a $30 \mathrm{~min}$ interval. This study established a sonoporation protocol in a clinical setting toward further development of this promising technique.

The drugs used together with ultrasound to treat solid tumors and cancer are listed in Table 2. Most of them are still in animal experiments using xenograft models in mice or rats. However, a genetically modified mouse model appears 
to more closely recapitulate the human disease compared to transplantation mouse models (xenograft), suggesting that insufficient drug delivery into the tumor is an important mechanism for apparent chemoresistance [113]. One of the barriers may be the presence of a prominent stromal matrix that separates blood vessels from tumor cells. In addition, there are a few reports on clinical applications.

Table 2. Summary of drugs used with ultrasound in the treatment of tumors

\begin{tabular}{cc}
\hline $\begin{array}{c}\text { Protoporphyrin IX (PPIX) and } \\
\text { hematoporphyrin (Hp) }\end{array}$ & S180 solid tumors in mice \\
\hline Photofrin II (PF) & $\begin{array}{c}\text { AH130 solid tumors in male Donryu rats, } \\
\text { colon 26 carcinoma }\end{array}$ \\
\hline ATX-70 & Colon 26 carcinoma tumor and Walker 256 tumor \\
in BALB/c mice
\end{tabular}


(continued) Table 2. Summary of drugs used with ultrasound in the treatment of tumors

\begin{tabular}{cc}
\hline Bleomycin & B-16 melanoma in SCID mice \\
\hline $\begin{array}{c}\text { Apo-2LTRAIL with Smac } \\
\text { peptides }\end{array}$ & Malignant glioma in athymic mice \\
\hline $\begin{array}{c}\text { Paxlitaxel-liposome- } \\
\text { microbubble complexes (PLMC) }\end{array}$ & 4T1 breast carcinoma in BALB/c mice \\
\hline Plasmid DNA with SonoVue & Hepa1-6 tumor in C57BL/6J female mice \\
\hline
\end{tabular}

\subsubsection{Angiogenesis}

Angiogenesis is the physiological process by which new blood vessels form from pre-existing vessels; this process is mostly responsible for blood vessel growth during development and in disease. Delivery of hepatocyte growth factor, either in the form of recombinant protein [114] or a plasmid [115], to rodents by UTMD has been found to result in proliferation and improvement in cardiac function [116]. The mRNA levels of various angiogenic factors as well as the blood flow rate were shown to increase significantly in the group treated with bFGF gene-loaded p-BLs and US exposure compared to the control group, which could be applicable to hind limb ischemia therapy. Skeletal muscle is a versatile tissue for UTMD, due to its ease of access (i.e., hind limb skeletal muscle) without surgery. The ability of intravascularly administered microbubbles to home specifically to the skeletal muscle vasculature is a key advantage over competing systems.

\subsubsection{Virotherapy}

Virotherapy is an important emerging therapeutic modality, especially when direct intratumoral injection of these self-amplifying tumor cell killing agents can be achieved [117]. The FDA has approved several adenoviruses for Phase III clinical trials. However, the use of virotherapy for the systemic treatment of metastatic disease may ultimately be limited by poor extravasation into tumors and inefficient intratumoral spread. It now seems that therapeutic ultrasound may offer a solution to this limitation and approach clinical applicability rapidly. However, the amount of virus delivered and the intratumoral distribution of these viruses should be measured quantitatively to evaluate the clinical outcome.

\subsubsection{Gene transfection}

Gene therapy has great potential to overcome the limitations of conventional drug and protein therapeutic delivery modalities for certain diseases, such as inherited immune deficiencies, cardiovascular disease, genetic disorders, and cancers. Several steps, such as cellular internalization, endosomal escape, nuclear transfer and intracellular transcription, should be rationally regulated 
to achieve efficient gene transfection. Among them, endosomal escape is considered one of the most important steps, because most carriers internalize into cells via the endocytic pathway, but cannot escape from endosomes, resulting in gene degradation in lysosomes. Therefore, the key factor in the success of gene therapy is an efficient and safe vector. In gene transfection, the efficient delivery of a few strands should be enough to provide an effect (one DNA molecule is sufficient to synthesize thousands of protein molecules) and subsequently obtain a sufficient therapeutic response. In the past, viral vectors predominated in gene therapy due to their ease of use, optimized internalization, efficient cytosolic release, direct and fast intracellular transport toward target, ready disassembly, and high transfection efficiency. However, several safety and immunogenicity concerns have restricted their clinical use [118]. Therefore, non-viral vectors are preferred. The ability of non-viral vectors to release nucleic acids intracellularly, while surviving low $\mathrm{pH}$ and digestive processes and avoiding premature decomplexation, is essential. Pharmacokinetic properties (i.e., distribution, circulation, and clearance) and gene transfer conditions (i.e., nucleic acid concentration, presence of serum, transfection time, and post-transfection time for gene expression) concomitantly affect the gene transfection efficiency.

Initial studies in the 1980s showed that US can enhance gene transfection by directly delivering DNA into the cytoplasm rather than simply co-injecting microbubbles with the unprotected plasmid intravenously, intraarterially or locally [119-123]. Without ultrasound exposure, very low transfection could be achieved in vivo. UTMB technology further increases transfection efficiency with more targeting specificity and gene protection. The integrity of the target is maintained, without infection. Acoustic energy can induce obvious apoptosis and restrain tumor cell proliferation via molecular mechanisms involving Bak, Bcl-2, and caspases, but not reactive oxygen species (ROS) [124], and the

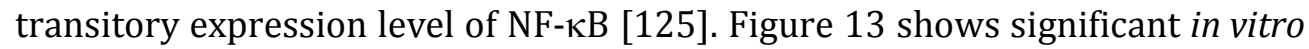
gene expression in cervical cancer cells using plasmids and microbubbles after ultrasound irradiation [126]. 

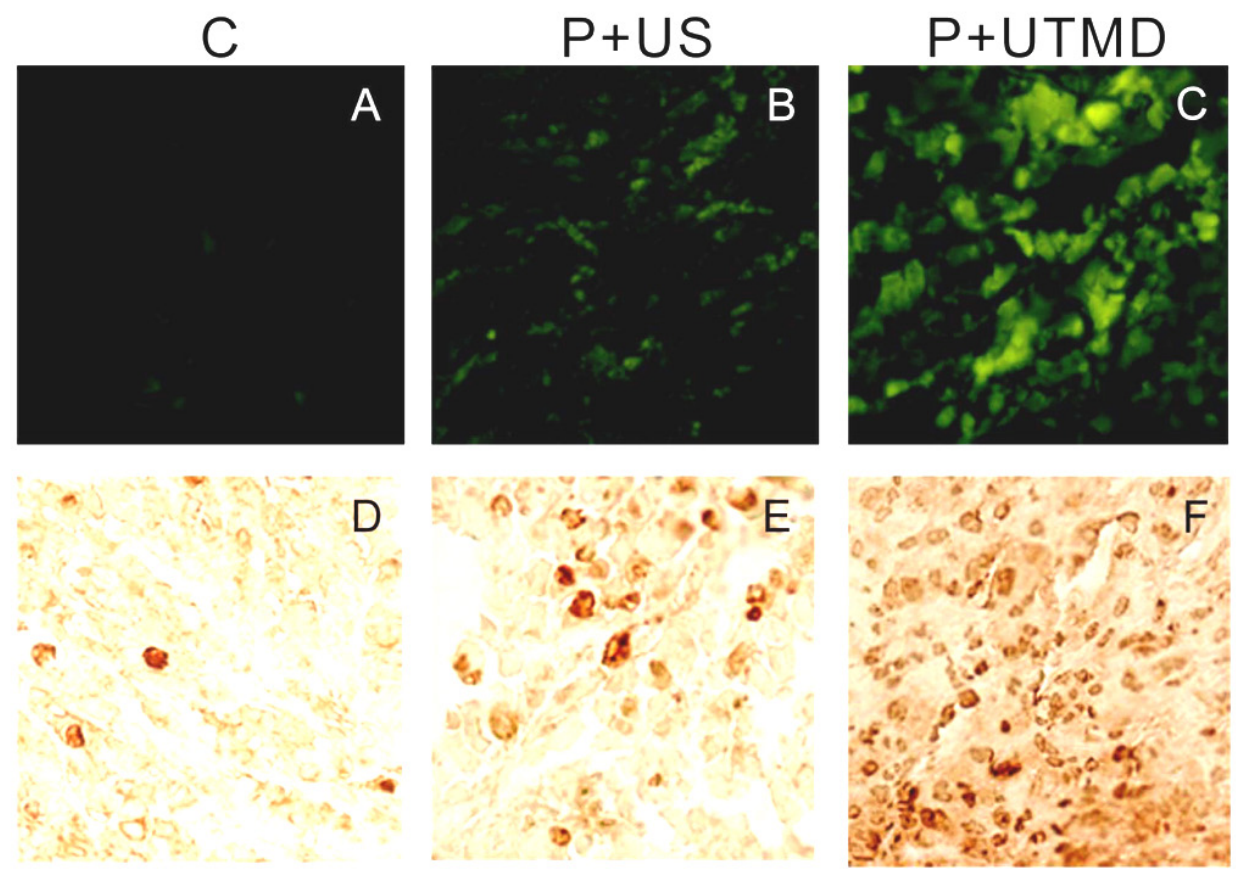

Figure 13. (A-C) TdT-mediated dUTP nick end labeling (TUNEL) and (D-F) diaminobenzidine (DAB) expression in cervical cancer cells in C: control group; $\mathrm{P}+\mathrm{US}$ : plasmid + ultrasound irradiation group;

P + UTMD: plasmid + microbubble + ultrasound irradiation group, courtesy of [126]

Nanoparticle-loaded microbubbles (mRNA-lipoplex loaded microbubbles) can result in significant expression of reporter genes, but essentially no gene expression can be found a week after ultrasound exposure. However, PEI/DNA complexes could prolong transgene expression for at least 15 days in vitro and 30 days in vivo [127]. Ultrasound-mediated gene therapy has been used efficiently to deliver both stem cell factor and vascular endothelial growth factor (VEGF) to infarcted heart muscle, resulting in increased expression of specific genes associated with increased vascular density derived from VEGF, along with improved myocardial perfusion and ventricular function [128]. Repeated ultrasound treatment for endostatin or calreticulin gene delivery to muscles can also produce a significant anti-tumor effect on distant orthotopic tumors in other organs, including the liver, brain, and lungs. Vaccination in the lymph nodes (intranodal vaccination) leads to a stronger immune response. Microbubbles are able to migrate to the lymph nodes after subcutaneous injection. Therefore, sonoporation has the potential of direct intranodal transfection in vivo with much less cost and time consumption in comparison to the ex vivo procedure [129]. 


\subsubsection{Blood-brain barrier (BBB) disruption}

The blood-brain barrier (BBB) is an endothelial barrier present in the brain microvasculature. It consists of tight junctions around all capillaries in the central nervous system (CNS), which separates circulating blood from the brain extracellular fluid and therefore hampers the movement of various substances (i.e., polar molecular) into the brain in a chemically stable environment. Microbubble cavitation alters the integrity of BBB components with no evidence of discrete lesions [130-132]. The disrupted BBB of the sonicated rabbit brain can repair itself within approximately 6 hours, and long-term follow-up showed nearly no damage [133]. So ultrasound-induced BBB disruption is a transient and reversible event [134]. The advance in this technology provides the opportunity to treat many formerly terminal conditions of the brain, not just limited to cancer.

An intravenously administered antibody, which targets the dopamine D4 receptor in the brain, has been shown to cross the BBB in a mouse model through the intact skull and recognize its antigens using MR-guided focused ultrasound $(690 \mathrm{kHz}$, burst length of $10 \mathrm{~ms}$, repetition frequency of $1 \mathrm{~Hz}$, sonication duration of $40 \mathrm{~s}$, and varied acoustic pressure of 0.6 to $1.1 \mathrm{MPa}$ ) and urocanic acid (UCA) injection [135]. BBB disruption was confirmed by contrast-enhanced T1-weighted MR and post-mortem by trypan blue staining. Little or no hemorrhage in the ultrasound focal region was observed at the pressure amplitude of lower than 0.8 MPa. Using the same protocol, the feasibility of delivering the chemotherapeutic agent Herceptin $(150 \mathrm{kDa})$, which is effective in the treatment of breast cancer metastases, to the normal murine brain was also investigated [135]. In addition, the delivery of DOX, encapsulated in long-circulating pegylated liposomes, was also examined in the normal rat brain, as shown in Figure 14 [136].
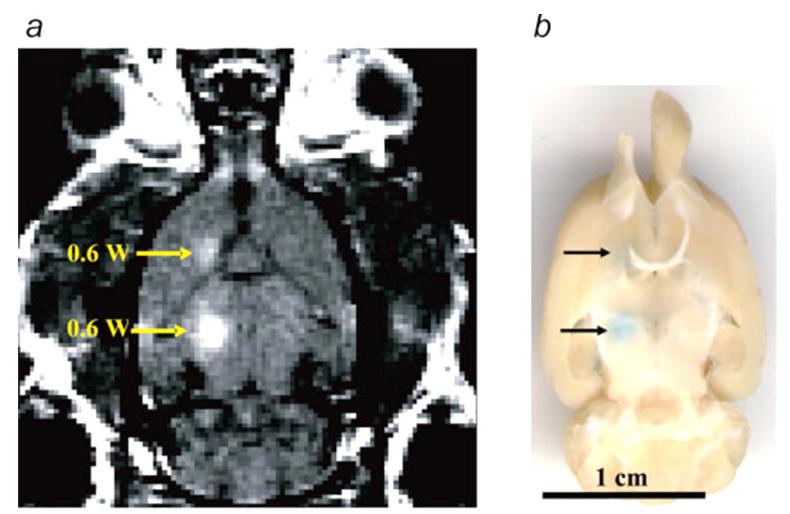

Figure 14. (a) Contrast-enhanced transversal (axial) T1-weighted MR fast spin-echo image after sonication at acoustic power of $0.6 \mathrm{~W}$. (b) The leakage of Trypan blue (arrows) from the vasculature into the brain parenchyma fixed in $10 \%$ buffered formalin phosphate $4 \mathrm{~h}$ after sonication, courtesy of [136] 


\subsection{FUTURE WORK}

There is plenty of evidence that ultrasound-mediated drug delivery and gene transfection in the presence of microbubbles is safe and effective. Ultrasound can be applied easily with a physical therapy apparatus or diagnostic equipment or using more complicated MRI-guided focused ultrasound systems. However, a lot of work is required to demonstrate the underlying mechanisms of action. For example, a clear understanding of the interaction between microbubbles and pDNA and the nuclear translocation mechanism of pDNA in the cytoplasm remains elusive and is ripe for investigation. New insights into sonoporation and the associated cellular mechanisms need to be further explored to allow optimal use of ultrasonic drug delivery [42]. The exact mechanism of ultrasound-mediated BBB penetration also needs to be elucidated. The molecular mechanism is subtle and elusive; it likely involves underlying DNA damage response pathways induced by ultrasound, which need further study. In vitro systems allow for the assessment of different mechanisms of action and good ultrasound dosimetry, but have little clinical relevance. It is difficult to quantify ultrasound exposure in vivo and to identify the individual elements responsible for the illustrated effects. New types of apoptosis-inducing methods specific to the molecular mechanism (i.e., caspases) have become a new research direction and represent an important strategy for anticancer therapy. To further develop the applications of ultrasound and introduce them into the clinic, interdisciplinary collaboration is in great need. Researchers in cellular physiology, genetics, physical chemistry, and acoustic physics should collaborate with new strategic partnerships to be established among industry, pharmaceutical companies, and academia in order to accelerate the development of this novel technology [137].

A new generation of delivery vehicles which are tailor-made for cavitation-enhanced drug delivery for cancer or other targets is under continuous development. On-demand drug delivery can be improved using multiple stimuli-responsive systems, which recognize the microenvironment and mimic the responsiveness of living organisms. The diversity of responsive materials can be assembled in different formats with great flexibility. However, despite of in vitro proof of concept, only a few stimuli-responsive systems have been tested in in vivo, and very few have reached the clinical stage. The complexity of architectures and difficulties in scaling up the synthesis are likely to hamper their translation from bench to bedside. Moreover, toxicity is multi-factorial, depending on the composition, physicochemical properties, route of administration, and dose. Therefore, the benefit-to-risk ratio has to be balanced [138].

In the near future, the regulatory status of ultrasound-mediated therapies will need to be defined for clinical use. To prepare a way for future clinical therapy, a large number of animal studies are required to evaluate the feasibility and efficacy of UTMD technology according to the regulations of medical 
authorities. Adverse effects, such as tissue damage and hemorrhage, should be avoided or minimized by decreasing microbubble concentrations and ultrasound energy. Moreover, careful monitoring is demanded in clinical settings to assure patient safety [139]. Passive acoustic mapping provides spatio-temporal information of cavitation activity using conventional ultrasound imagers, and could thus inform clinicians when and where a therapeutic agent has been successfully delivered [140,141]. To translate UTMD into clinical trials, more robust ultrasound parameters must be defined, such as the pressure threshold for cavitation initiation [142]. Both the enhanced permeability and retention effect and ligand recognition, which may be a consequence of the stochastic nature of ligand-receptor interactions, which is difficult in the control of drug release from targeting nanocarriers, still remains questionable in the clinic. The use of viral structures (i.e., adenovirus), regarded as therapeutic biological products by the FDA, in combination with microbubbles and ultrasound, might also reach clinical trials within a few years, even if negligible viral transfection occurs in remote organs due to safety concerns [116]. More complicated structures, which combine nucleic acids and ultrasound-triggered carriers into micro or nanoparticles, will take many years to bring to clinic because they will be regarded as drugs by the FDA.

\subsection{CONCLUSION}

Ultrasound-mediated drug delivery has been investigated for decades. With the development and application of micro or nanobubbles, its efficiency and efficacy have been enhanced significantly due to cavitation effects. The design of specifically-targeted bubbles with loaded with drugs and/or genetic material makes theranostics possible, which will not only increase local transport but also reduce immature release and unexpected side effects. Because of the popularity of sonographic systems in hospitals and their easy operation, this technology may have great potential for clinical translation. Although most successful reports are at the stage of animal experiments, several drugs are in different phases of clinical trials and may be approved within a few years. In order to further develop this technology, the mechanisms of bubble interactions with drugs and tumor cells should be better understood. Extensive collaboration between academia, hospitals, the pharmaceutical industry, the ultrasound industry, and medicine regulatory authorities is necessary to push this technology forward. 


\section{REFERENCES}

1. M. Arruebo. Wiley Interdiscip. Rev. Nanomed. Nanobiotechnol. 4 (2012) 16-30.

2. D.M. McDonald, P. Baluk. Cancer Res. 62 (2002) 5381-5385.

3. Q.A. Pankhurst, J. Connolly, S. Jones, J. Dobson. J. Phys. D Appl. Phys. 36 (2003) R167-R181.

4. K. Strebhardt, A. Ullich. Nat. Rev. Cancer 8 (2008) 473-480.

5. A.S. Lübbe, C. Alexiou, C. Bergemann. J. Surg. Res. 95 (2001) 200-206.

6. H. Hellebust, C. Christiansen, T. Skotland. Biotechnol. Appl. Biochem. 18 (1993) 227-237.

7. A.H. Myrset, H. Nicolaysen, K. Toft, C. Christiansen, T. Skotland. Biotechnol. Appl. Biochem. 24 (1996) 145-153.

8. C. Christiansen, T. Skotland. Biotechnol. Appl. Biochem. 55 (2010) 121-130.

9. S. Podell, C. Burrascano, M. Gaal, B. Golec, J. Maniquis, P. Mehlhaff. Biotechnol. Appl. Biochem. 30 (1999) 213-223.

10. P.C. Sontum. Ultrasound Med. Biol. 34 (2008) 824-833.

11. S.B. Feinstein. Am. J. Physiol. Heart Circ. Physiol. 287 (2004) H450-H457.

12. M.L. Main, M.G. Hibberd, A. Ryan, T.J. Lowe, P. Miller, G. Bhat. JACC Cardiovasc. Imaging 7 (2014) 40-48.

13. R. Li, Y. Guo, X. Hua, Y. He, J. Ding, A. Guo, M. Luo. J. Clin. Ultrasound 35 (2007) 109-117.

14. J. Horvath. Strahlentherapie 75 (1944) 119-125.

15. A. Szent-Györgi. Nature 131 (1933) 278.

16. G.A. Husseini, W.G. Pitt. Adv. Drug Deliv. Rev. 60 (2008) 1137-1152.

17. Y. Taniyama, K. Tachibana, K. Hiraoka, T. Namba, K. Yamasaki, N. Hashiya, M. Aoki, T. Ogihara, K. Yasufumi, R. Morishita. Circulation 105 (2002) 1233-1239.

18. T. Li, K. Tachibana, M. Kuroki, M. Kuroki. Radiology 229 (2003) 423-428.

19. E.C. Unger, T. Porter, W. Culp, R. Labell, T. Matsunaga, R. Zutshi. Adv. Drug Deliv. Rev. 56 (2004) 1291-1314.

20. S. Sonoda, K. Tachibana, E. Uchino, A. Okubo, M. Yamamoto, K. Sakoda, T. Hisatomi, K.-H. Sonoda, Y. Negishi, Y. Izumi. Invest. Ophthalmol. Vis. Sci. 47 (2006) 558-564.

21. K. Otani, K. Yamahara, S. Ohnishi, H. Obata, S. Kitamura, N. Nagaya. J. Control. Release 133 (2009) 146-153.

22. B. Sumer, J. Gao. Nanomedicine 3 (2008) 137-140.

23. B. Billard, K. Hynynen, R. Roemer. Ultrasound Med. Biol. 16 (1990) 409-420.

24. A. Partanen, P.S. Yarmolenko, A. Viitala, S. Appanaboyina, D. Haemmerich, A. Ranjan, G. Jacobs, D. Woods, J. Enholm, B.J. Wood. Int. J. Hyperther. 28 (2012) 320-336.

25. R.E. Apfel, C.K. Holland. Ultrasound Med. Biol. 17 (1991) 179-185.

26. R. Suzuki, Y. Oda, N. Utoguchi, K. Maruyama. J. Control. Release 149 (2011) 36-41.

27. A. Schroeder, R. Honen, K. Turjeman, A. Gabizon, J. Kost, Y. Barenholz. J. Control. Release 137 (2009) 63-68.

28. M. Bazan-Peregrino, C.D. Arvanitis, B. Rifai, L.W. Seymour, C.-C. Coussios. J. Control. Release 157 (2012) 235-242.

29. C.C. Coussios, R.A. Roy. Annu. Rev. Fluid Mech. 40 (2008) 395-420. 
30. C.D. Arvanitis, M. Bazan-Peregrino, B. Rifai, L.W. Seymour, C.C. Coussios. Ultrasound Med. Biol. 37 (2011) 1838-1852.

31. P. Tho, R. Manasseh, A. Ooi. J. Fluid Mech. 576 (2007) 191-233.

32. J.P. Christiansen, B.A. French, A.L. Klibanov, S. Kaul, J.R. Lindner. Ultrasound Med. Biol. 29 (2003) 1759-1767.

33. R.K. Schlicher, H. Radhakrishna, T.P. Tolentino, R.P. Apkarian, V. Zarnitsyn, M.R. Prausnitz. Ultrasound Med. Biol. 32 (2006) 915-924.

34. C.X. Deng, F. Sieling, H. Pan, J. Cui. Ultrasound Med. Biol. 30 (2004) 519-526.

35. A. Van Wamel, K. Kooiman, M. Harteveld, M. Emmer, J. Folkert, M. Versluis, N. De Jong. J. Control. Release 112 (2006) 149-155.

36. L. Juffermans, P.A. Dijkmans, R. Musters, C.A. Visser, O. Kamp. Am. J. Physiol. Heart Circ. Physiol. 291 (2006) H1595-H1601.

37. M. Böhmer, C. Chlon, B. Raju, C. Chin, T. Shevchenko, A. Klibanov. J. Control. Release 148 (2010) 18-24.

38. R. Deckers, C.T. Moonen. J. Control. Release 148 (2010) 25-33.

39. A.L. Klibanov, T.I. Shevchenko, B.I. Raju, R. Seip, C.T. Chin. J. Control. Release 148 (2010) 13-17.

40. C.-Y. Lin, T.-M. Liu, C.-Y. Chen, Y.-L. Huang, W.-K. Huang, C.-K. Sun, F.-H. Chang, W.-L. Lin. J. Control. Release 146 (2010) 291-298.

41. S. Mehier-Humbert, T. Bettinger, F. Yan, R.H. Guy. J. Control. Release 104 (2005) 213-222.

42. B. Geers, H. Dewitte, S.C. De Smedt, I. Lentacker. J. Control. Release 164 (2012) 248-255.

43. B.D. Meijering, L.J. Juffermans, A. van Wamel, R.H. Henning, I.S. Zuhorn, M. Emmer, A.M. Versteilen, W.J. Paulus, W.H. van Gilst, K. Kooiman. Circ. Res. 104 (2009) 679-687.

44. Z. Chen, K. Liang, M. Xie, X. Wang, Q. Lü, J. Zhang. Mol. Biol. Rep. 36 (2009) 2059-2067.

45. H. Bayir, V.E. Kagan. Crit. Care 12 (2008) 206.

46. O. Raab. Zeitung Biol. 39 (1900) 524-526.

47. K.R. Weishaupt, C.J. Gomer, T.J. Dougherty. Cancer Res. 36 (1976) 2326-2329.

48. E. Stride, M. Edirisinghe. Soft matter 4 (2008) 2350-2359.

49. S. Sirsi, M. Borden. Bubble Sci. Eng. Technol. 1 (2009) 3-17.

50. S. Hernot, A.L. Klibanov. Adv. Drug Deliv. Rev. 60 (2008) 1153-1166.

51. M.S. Tartis, D.E. Kruse, H. Zheng, H. Zhang, A. Kheirolomoom, J. Marik, K.W. Ferrara. J. Control. Release 131 (2008) 160-166.

52. E.C. Unger, T.P. McCreery, R.H. Sweitzer, V.E. Caldwell, Y. Wu. Invest Radiol. 33 (1998) 886.

53. E.C. Unger, E. Hersh, M. Vannan, T.O. Matsunaga, T. McCreery. Prog. Cardiovasc. Dis. 44 (2001) 45-54.

54. Y.F. Dufrêne, W.R. Barger, J.-B.D. Green, G.U. Lee. Langmuir 13 (1997) 4779-4784.

55. E.C. Unger, T.O. Matsunaga, T. McCreery, P. Schumann, R. Sweitzer, R. Quigley. Eur. J. Radiol. 42 (2002) 160-168.

56. P.A. Frenkel, S. Chen, T. Thai, R.V. Shohet, P.A. Grayburn. Ultrasound Med. Biol. 28 (2002) 817-822.

57. I. Lentacker, B.G. De Geest, R.E. Vandenbroucke, L. Peeters, J. Demeester, S.C. De Smedt, N.N. Sanders. Langmuir 22 (2006) 7273-7278. 
58. M.A. Borden, C.F. Caskey, E. Little, R.J. Gillies, K.W. Ferrara. Langmuir 23 (2007) 9401-9408.

59. R.E. Vandenbroucke, I. Lentacker, J. Demeester, S.C. De Smedt, N.N. Sanders. J. Control. Release 126 (2008) 265-273.

60. I. Lentacker, S.C. De Smedt, N.N. Sanders. Soft Matter 5 (2009) 2161-2170.

61. L.C. Phillips, A.L. Klibanov, D.K. Bowles, M. Ragosta, J.A. Hossack, B.R. Wamhoff. J. Vasc. Res. 47 (2010) 270-274.

62. L.C. Phillips, A.L. Klibanov, B.R. Wamhoff, J.A. Hossack. Ultrasound Med. Biol. 36 (2010) 1470-1480.

63. X.-Q. Zhang, J. Intra, A.K. Salem. J. Microencapsulation 25 (2008) 1-12.

64. S.R. Sirsi, S.L. Hernandez, L. Zielinski, H. Blomback, A. Koubaa, M. Synder, S. Homma, J.J. Kandel, D.J. Yamashiro, M.A. Borden. J. Control. Release 157 (2012) 224-234.

65. A. El-Aneed. J. Control. Release 94 (2004) 1-14.

66. D.W. Pack, A.S. Hoffman, S. Pun, P.S. Stayton. Nat. Rev. Drug. Discov. 4 (2005) 581-593.

67. T.G. Park, J.H. Jeong, S.W. Kim. Adv. Drug Deliv. Rev. 58 (2006) 467-486.

68. S. Hernot, A.L. Klibanov. Adv. Drug Deliv. Rev. 60 (2008) 1153-1166.

69. G.E. Weller, F.S. Villanueva, E.M. Tom, W.R. Wagner. Biotechnol. Bioeng. 92 (2005) 780-788.

70. A.L. Klibanov. Adv. Drug Deliv. Rev. 37 (1999) 139-157.

71. 71. C. Sun, J.S. Lee, M. Zhang. Adv. Drug Deliv. Rev. 60 (2008) 1252-1265.

72. J. Owen, Q. Pankhurst, E. Stride. Int. J. Hyperther. 28 (2012) 362-373.

73. B. Polyak, G. Friedman. Expert Opin. Drug Del. 6 (2009) 53-70.

74. F. Yang, L. Li, Y. Li, Z. Chen, J. Wu, N. Gu. Phys. Med. Biol. 53 (2008) 6129-6141.

75. T. Neuberger, B. Schöpf, H. Hofmann, M. Hofmann, B. Von Rechenberg. J. Magn. Magn. Mater. 293 (2005) 483-496.

76. M. Willard, L. Kurihara, E. Carpenter, S. Calvin, V. Harris. Int. Mater. Rev. 49 (2004) 125-170.

77. S.-L. Huang, A.J. Hamilton, E. Pozharski, A. Nagaraj, M.E. Klegerman, D.D. McPherson, R.C. MacDonald. Ultrasound Med. Biol. 28 (2002) 339-348.

78. R. Nahire, S. Paul, M.D. Scott, R.K. Singh, W.W. Muhonen, J. Shabb, K.N. Gange, D. Srivastava, K. Sarkar, S. Mallik. Mol. Pharm. 9 (2012) 2554-2564.

79. J.N. Weinstein, R.L. Magin, R.L. Cysyk, D.S. Zaharko. Cancer Res. 40 (1980) 1388-1395.

80. S. Dromi, V. Frenkel, A. Luk, B. Traughber, M. Angstadt, M. Bur, J. Poff, J. Xie, S.K. Libutti, K.C. Li. Clin. Cancer Res. 13 (2007) 2722-2727.

81. K. Hynynen, N. McDannold, N. Vykhodtseva, F.A. Jolesz. Radiology 220 (2001) 640-646.

82. A. Gasselhuber, M.R. Dreher, A. Partanen, P.S. Yarmolenko, D. Woods, B.J. Wood, D. Haemmerich. Int. J. Hyperther. 28 (2012) 337-348.

83. G. ter Haar. Int. J. Hyperther. 28 (2012) 279-281.

84. A. Yudina, C. Moonen. Int. J. Hyperther. 28 (2012) 311-319.

85. A. Kheirolomoom, P.A. Dayton, A.F. Lum, E. Little, E.E. Paoli, H. Zheng, K.W. Ferrara. J. Control. Release 118 (2007) 275-284.

86. B. Geers, I. Lentacker, N.N. Sanders, J. Demeester, S. Meairs, S.C. De Smedt. J. Control. Release 152 (2011) 249-256.

87. D. Yang, Y. Gao, K. Tan, Z. Zuo, W. Yang, X. Hua, P. Li, Y. Zhang, G. Wang. Gene Ther. 20 (2013) 1140-1148. 
88. H.-I. Chang, M.-Y. Cheng, M.-K. Yeh. Sci. Rep. 1 (2012) 195-202.

89. T.M. Allen, P.R. Cullis. Adv. Drug Deliv. Rev. 65 (2013) 36-48.

90. A.F.H. Lum, B. M.A., P.A. Dayton, D.E. Kruse, S.I. Simon, K.W. Ferrara. J. Control. Release 111 (2006) 128-134.

91. M.L. Fabiilli, K.J. Haworth, N.H. Fakhri, O.D. Kripfgans, P.L. Carson, J.B. Fowlkes. IEEE Trans. Ultrason. Ferroelect. Freq. Control 56 (2009) 1006-1017.

92. P.S. Sheeran, S.H. Luois, L.B. Mullin, T.O. Matsunaga, P.A. Dayton. Biomaterials 33 (2012) 3262-3269.

93. R. Singh, G.A. Husseini, W.G. Pitt. Ultrason. Sonochem. 19 (2012) 1120-1125.

94. T.O. Matsunaga, P.S. Sheeran, S. Luois, J.E. Streeter, L.B. Mullin, B. Banerjee, P.A. Dayton. Theranostics 2 (2012) 1185.

95. H. Eliyahu, N. Servel, A. Domb, Y. Barenholz. Gene Ther. 9 (2002) 850-858.

96. S. Even-Chen, Y. Barenholz. BBA-Biomembranes 1509 (2000) 176-188.

97. M.F. Chung, K.J. Chen, H.F. Liang, Z.X. Liao, W.T. Chia, Y. Xia, H.W. Sung. Angew. Chem. Int. Ed. Engl. 124 (2012) 10236-10240.

98. E. Unger, T. Porter, J. Lindner, P. Grayburn. Adv. Drug Deliv. Rev. 72 (2014) 110-126.

99. C.A. Molina, A.D. Barreto, G. Tsivgoulis, P. Sierzenski, M.D. Malkoff, M. Rubiera, N. Gonzales, R. Mikulik, G. Pate, J. Ostrem. Ann. Neurol. 66 (2009) 28-38.

100. A.V. Alexandrov, C.A. Molina, J.C. Grotta, Z. Garami, S.R. Ford, J. Alvarez-Sabin, J. Montaner, M. Saqqur, A.M. Demchuk, L.A. Moyé. N. Engl. J. Med. 351 (2004) 2170-2178.

101. S. Meairs, W. Culp. Cerebrovasc. Dis. 27 (2008) 55-65.

102. M. Daffertshofer, A. Gass, P. Ringleb, M. Sitzer, U. Sliwka, T. Els, O. Sedlaczek, W.J. Koroshetz, M.G. Hennerici. Stroke 36 (2005) 1441-1446.

103. X. Hua, P. Liu, Y.-H. Gao, K.-B. Tan, L.-N. Zhou, Z. Liu, X. Li, S.-W. Zhou, Y.-J. Gao. J. Thromb. Thrombolysis 30 (2010) 29-35.

104. J.E. Leeman, J.S. Kim, T. Francois, X. Chen, K. Kim, J. Wang, X. Chen, F.S. Villanueva, J.J. Pacella. Ultrasound Med. Biol. 38 (2012) 1589-1598.

105. C. Newman, T. Bettinger. Gene Ther. 14 (2007) 465-475.

106. Z.-Y. Chen, Y.-X. Wang, Y.-Z. Zhao, F. Yang, J.-B. Liu, Y. Lin, J.-Y. Liao, Y.-Y. Liao, Q.-L. Zhou. Curr. Mol. Med. 14 (2014) 723-736.

107. G. Oosterhof, E. Cornel, G. Smits, F. Debruyne, J. Schalken. Eur. Urol. 32 (1996) 91-95.

108. F. Wu, Z.-B. Wang, C.-B. Jin, J.-P. Zhang, W.-Z. Chen, J. Bai, J.-Z. Zou, H. Zhu. Ultrasound Med. Biol. 30 (2004) 511-517.

109. Y. Endo-Takahashi, Y. Negishi, A. Nakamura, D. Suzuki, S. Ukai, K. Sugimoto, F. Moriyasu, N. Takagi, R. Suzuki, K. Maruyama. Biomaterials 34 (2013) 2807-2813.

110. F. Wu, Z.-Y. Shao, B.-J. Zhai, C.-L. Zhao, D.-M. Shen. Ultrasound Med. Biol. 37 (2011) 151-159.

111. J.-M. Escoffire, A. Novell, M. de Smet, A. Bouakaz. Phys. Med. Biol. 58 (2013) 8135-8151.

112. S. Kotopoulis, G. Dimcevski, O.H. Gilja, D. Hoem, M. Postema. Med. Phys. 40 (2013) 072902.

113. K. Olive, M. Jacobetz, C. Davidson, A. Gopinathan, D. McIntyre, D. Honess, B. Madhu, M. Goldgraben, M. Caldwell, D. Allard. Science 324 (2009) 1457-1461.

114. M. Iwasaki, Y. Adachi, T. Nishiue, K. Minamino, Y. Suzuki, Y. Zhang, K. Nakano, Y. Koike, J. Wang, H. Mukaide. Stem Cells 23 (2005) 1589-1597. 
115. I. Kondo, K. Ohmori, A. Oshita, H. Takeuchi, S. Fuke, K. Shinomiya, T. Noma, T. Namba, M. Kohno. J. Am. Coll. Cardiol. 44 (2004) 644-653.

116. J.J. Rychak, A.L. Klibanov. Adv. Drug Deliv. Rev. 72 (2014) 82-93.

117. D. Kirn. Expert Opin. Biol. Th. 1 (2001) 525-538.

118. E. Marshall. Science 286 (1999) 2244-2245.

119. M. Fechheimer, J.F. Boylan, S. Parker, J.E. Sisken, G.L. Patel, S.G. Zimmer. Proc. Natl. Acad. Sci. 84 (1987) 8463-8467.

120. W.J. Greenleaf, M.E. Bolander, G. Sarkar, M.B. Goldring, J.F. Greenleaf. Ultrasound Med. Biol. 24 (1998) 587-595.

121. A. Lawrie, A. Brisken, S. Francis, D. Cumberland, D. Crossman, C. Newman. Gene Ther. 7 (2000) 2023-2027.

122. Y. Taniyama, K. Tachibana, K. Hiraoka, M. Aoki, S. Yamamoto, K. Matsumoto, T. Nakamura, T. Ogihara, Y. Kaneda, R. Morishita. Gene Ther. 9 (2002) 372380.

123. S. Mehier-Humbert, T. Bettinger, F. Yan, R.H. Guy. J. Control. Release 104 (2005) 203-211.

124. M. Kinoshita, Y. Eguchi, K. Hynynen. Biochem. Biophys. Res. Commun. 353 (2007) 515-521.

125. Z. Jiang, W. Wu, M. Qian. Cancer Cell Int. 12 (2012) 1-7.

126. Z.-Y. Chen, K. Liang, Y. Lin, F. Yang. Int. J. Mol. Sci. 14 (2013) 1763-1777.

127. J.-L. Lee, C.-W. Lo, S.-M. Ka, A. Chen, W.-S. Chen. J. Control. Release 160 (2012) 64-71.

128. H. Fujii, Z. Sun, S.-H. Li, J. Wu, S. Fazel, R.D. Weisel, H. Rakowski, J. Lindner, R.-K. Li. JACC Cardiovasc. Imaging 2 (2009) 869-879.

129. A. Sever, S. Jones, K. Cox, J. Weeks, P. Mills, P. Jones. Br. J. Surg. 96 (2009) 1295-1299.

130. H. Ballantine, T. Hueter, W. Nauta, D. Sosa. J. Exp. Med. 104 (1956) 337-360.

131. N. Vykhodtseva, K. Hynynen, C. Damianou. Ultrasound Med. Biol. 20 (1994) 987-1000.

132. B. Baseri, J.J. Choi, Y.-S. Tung, E.E. Konofagou. Ultrasound Med. Biol. 36 (2010) 1445-1459.

133. N. McDannold, N. Vykhodtseva, S. Raymond, F.A. Jolesz, K. Hynynen. Ultrasound Med. Biol. 31 (2005) 1527-1537.

134. K. Hynynen, N. McDannold, N.A. Sheikov, F.A. Jolesz, N. Vykhodtseva. Neuroimage 24 (2005) 12-20.

135. M. Kinoshita, N. McDannold, F.A. Jolesz, K. Hynynen. Proc. Natl. Acad. Sci. 103 (2006) 11719-11723.

136. L.H. Treat, N. McDannold, N. Vykhodtseva, Y. Zhang, K. Tam, K. Hynynen. Int. J. Cancer 121 (2007) 901-907.

137. J. Castle, M. Butts, A. Healey, K. Kent, M. Marino, S.B. Feinstein. Am. J. Physiol. Heart Circ. Physiol. 304 (2013) H350-H357.

138. S. Mura, J. Nicolas, P. Couvreur. Nat. Mater. 12 (2013) 991-1003.

139. N.A. Geis, H.A. Katus, R. Bekeredjian. Curr. Pharm. Des. 18 (2012) 2166-2183.

140. 140. M. Gyongy, C.-C. Coussios. IEEE Trans. Biomed. Eng. 57 (2010) 48-56.

141. C.R. Jensen, R.W. Ritchie, M. Gyöngy, J.R. Collin, T. Leslie, C.-C. Coussios. Radiology 262 (2012) 252-261.

142. S. Mo, C.-C. Coussios, L. Seymour, R. Carlisle. Expert Opin. Drug Del. 9 (2012) 1525-1538. 